\title{
Retrieval of aerosol microphysical and optical properties above liquid clouds from POLDER/PARASOL polarization measurements
}

\author{
F. Waquet, C. Cornet, J.-L. Deuzé, O. Dubovik, F. Ducos, P. Goloub, M. Herman, T. Lapyonok, L. C. Labonnote, \\ J. Riedi, D. Tanré, F. Thieuleux, and C. Vanbauce \\ Laboratoire d'Optique Atmosphérique, CNRS-INSU - UMR8518, Université Lille 1, Villeneuve-d'Ascq, France
}

Correspondence to: F. Waquet (fabien.waquet@univ-lille1.fr)

Received: 20 July 2012 - Published in Atmos. Meas. Tech. Discuss.: 27 August 2012

Revised: 17 February 2013 - Accepted: 19 February 2013 - Published: 15 April 2013

\begin{abstract}
Most of the current aerosol retrievals from passive sensors are restricted to cloud-free scenes, which strongly reduces our ability to monitor the aerosol properties at a global scale and to estimate their radiative forcing. The presence of aerosol above clouds (AAC) affects the polarized light reflected by the cloud layer, as shown by the spaceborne measurements provided by the POlarization and Directionality of Earth Reflectances (POLDER) instrument on the PARASOL satellite. In a previous work, a first retrieval method was developed for AAC scenes and evaluated for biomassburning aerosols transported over stratocumulus clouds. The method was restricted to the use of observations acquired at forward scattering angles (90-120 $0^{\circ}$ where polarized measurements are highly sensitive to fine-mode particle scattering. Non-spherical particles in the coarse mode, such as mineral dust particles, do not much polarize light and cannot be handled with this method. In this paper, we present new developments that allow retrieving also the properties of mineral dust particles above clouds. These particles do not much polarize light but strongly reduce the polarized cloud bow generated by the liquid cloud layer beneath and observed for scattering angles around $140^{\circ}$. The spectral attenuation can be used to qualitatively identify the nature of the particles (i.e. accumulation mode versus coarse mode, i.e. mineral dust particles versus biomass-burning aerosols), whereas the magnitude of the attenuation is related to the optical thickness of the aerosol layer. We also use the polarized measurements acquired in the cloud bow to improve the retrieval of both the biomass-burning aerosol properties and the cloud microphysical properties. We provide accurate polarized radiance calculations for AAC scenes and evaluate the contribution of the POLDER polarization measurements
\end{abstract}

for the simultaneous retrieval of the aerosol and cloud properties. We investigate various scenes with mineral dust particles and biomass-burning aerosols above clouds. For clouds, our results confirm that the droplet size distribution is narrow in high-latitude ocean regions and that the droplet effective radii retrieved from both polarization measurements and from total radiance measurements are generally close for AAC scenes (departures smaller than $2 \mu \mathrm{m}$ ). We found that the magnitude of the primary cloud bow cannot be accurately estimated with a plane parallel transfer radiative code. The errors for the modeling of the polarized cloud bow are between 4 and $8 \%$ for homogenous cloudy scenes, as shown by a 3-D radiative transfer code. These effects only weakly impact the retrieval of the Aerosol Optical Thickness (AOT) performed with a mineral dust particle model for which the microphysical properties are entirely known (relative error smaller than $6 \%$ ). We show that the POLDER polarization measurements allow retrieving the AOT, the finemode particle size, the Ångström exponent and the fraction of spherical particles. However, the complex refractive index and the coarse-mode particle size cannot be accurately retrieved with the present polarization measurements. Our complete and accurate algorithm cannot be applied to process large amounts of data, so a simpler algorithm was developed to retrieve the AOT and the Ångström exponent above clouds in an operational way. Illustrations are provided for July-August 2008 near the African coast. Large mean AOTs above clouds at $0.865 \mu \mathrm{m}(>0.3)$ are retrieved for oceanic regions near the coasts of South Africa that correspond to biomass-burning aerosols, whereas even larger mean AOTs above clouds for mineral dust particles $(>0.6)$ are also retrieved near the coasts of Senegal. For these regions and time 
period, the direct AAC radiative forcing is likely to be significant. The final aim of this work is the global monitoring of the AAC properties and the estimation of the direct aerosol radiative forcing in cloudy scenes.

\section{Introduction}

Aerosols directly affect the climate of the Earth by interacting with solar and thermal infrared radiation. These atmospheric particles scatter the sunlight and reflect a part of it back into space. This effect is called the "direct aerosol effect" and cools the Earth's surface. By absorbing the solar light, absorbing aerosols further cool the surface but also warm the corresponding layer of the atmosphere where they reside. This may modify the vertical profile of temperature in the atmosphere, which affects the process of evaporation and cloud formation (Ackerman et al., 2000). This so-called "semi-direct aerosol effect" is currently not well quantified and might partially compensate for the aerosol direct effect at a regional scale (Ramanathan et al., 2001). By acting as cloud condensation nuclei, these particles also have significant effects on the cloud microphysical properties (Bréon et al., 2002). Increasing aerosol concentrations results in an increase of cloud condensation nuclei, which can eventually cause a decrease in cloud droplet size; both effects leading to an increase in cloud reflectivity (Twomey, 1977). This process is called the first "aerosol indirect effect" and contributes to cool the Earth atmosphere system. The reduction in cloud droplet size might also modify cloud lifetime and change precipitation efficiency (Rosenfeld, 2000). This process is referred to as the second aerosol indirect effect. Only the direct effect and the first indirect effect are currently quantified at a global scale with a level of knowledge qualified as medium and poor, respectively, according to Forster et al. (2007).

In order to better understand the role of the aerosols on the Earth's climate, the spatial and temporal variability of their concentrations and microphysical properties have to be accurately measured and modeled. The aerosol microphysical properties are the particle size distribution, shape and composition. The aerosol size distribution is typically bimodal with a coarse and a fine mode (i.e. accumulation mode). Fine-mode particles are associated with size ranging between roughly 0.06 and $0.6 \mu \mathrm{m}$, whereas coarse-mode particles are larger than $0.6 \mu \mathrm{m}$ (in radius). The aerosol microphysical properties exhibit a high variability at a global scale since these particles are produced by various processes and sources and also because their properties evolve along the transport process in the atmosphere. Anthropogenic aerosols can be directly emitted in the atmosphere (e.g. pollutant particles from industrial activities or biomass-burning aerosols from manmade vegetation fires) or result from the conversion of anthropogenic gas into particles (e.g. sulphate aerosols). Most of them are in the accumulation mode. Natural processes also generate aerosols, for instance the mineral dust particles and the maritime aerosols (i.e. sea salt) which result from the mechanical action of the wind on the desert and ocean surfaces, respectively. Other natural aerosols include volcanic dust aerosols, pollens and ashes from wild vegetation fires. Natural aerosols mainly contribute to the coarse mode with the mineral dust particles being the major contributor to the total amount of natural aerosols present in the troposphere (Kaufman et al., 2002).

Biomass-burning aerosols are usually injected at high altitude in the atmosphere $(>6 \mathrm{~km})$ and can be transported over considerable distance and sometimes above clouds. Manmade vegetation fires are frequent in South Africa between June and September (Tanré et al., 2001). Smoke plumes are uplifted above the continent at high altitude and, because of local meteorological conditions, transported primarily toward the west over the Atlantic Ocean. Persistent decks of low-level stratiform clouds usually cover this part of the Atlantic Ocean during the same time period, and the transport of biomass-burning aerosols above clouds is frequent in this region. The transport of Saharan mineral dust is also frequent across the Atlantic, and dust plumes are regularly transported above low-level clouds off the coasts of Senegal (Haywood et al., 2003). Other types of aerosols such as volcanic dust particles and pollutant particles (Hsu et al., 2003; Coddington et al., 2010) were also observed above clouds in other regions of the world. The most commonly observed situation corresponds to an elevated aerosol layer suspended above a low-level liquid water cloud, but properties of aerosol above clouds (AAC) have not been extensively studied yet. Biomass-burning aerosols have strong absorption properties due to their high concentration in black carbon (Haywood and Boucher, 2000). When located above a cloud, high-absorbing particles reduce the brightness of the scene (i.e. the cloud albedo), which causes a local positive radiative forcing that contributes to locally warming the atmosphere. Regional studies of the AAC radiative forcing has been achieved (Chand et al., 2009; Peters et al., 2011; De Graaf et al., 2012). However, this forcing is currently not constrained at a global scale, which explains why the estimation of the direct effect of biomass-burning aerosols currently remains poorly estimated (Forster et al., 2007). The presence of biomass-burning aerosols above clouds may also affect the dynamical evolution of clouds (Johnson et al., 2004). The induced effects could be a reduction in cloud top altitude and a cloud thickening that might result in an enhancement of the cloud albedo (Wilcox et al., 2012).

In order to better quantify the aerosol radiative forcing in the case of AAC scenes, an accurate knowledge of the properties (primarily load, absorption and size) of the aerosols located above the clouds is required. These properties allow estimating the aerosol optical parameters and their spectral dependence that controls the aerosol radiative forcing. The first optical parameter to be determined is the Aerosol Optical Thickness (AOT), which is a measure of 
the radiation extinction due to particle scattering and absorption, integrated over the atmospheric column. Another important aerosol parameter for determining the signs (cooling or warming) of the effect over a bright target is the aerosol single scattering albedo (SSA). To estimate the aerosol radiative forcing (which is the radiative effect due to human activities), the nature of the particles must be identified (natural or anthropogenic), which requires the knowledge of the particle microphysics together with some information on their geographical origin. It is also required to determine the cloud albedo (Keil and Haywood, 2003), and to a lesser extent the respective vertical profiles of the aerosol and cloud layers.

Passive remote sensing by satellite provides observations at a global scale and on a daily basis and therefore constitutes a well-suited tool for aerosol (and cloud) monitoring (Kaufman et al., 2002). However, most of the current passive remote sensing techniques rely on the use of cloud-screening algorithms before retrieving the aerosol properties. This limits our ability to estimate the aerosol direct effects to only cloud-free scenes and restricts our capacity to estimate the total amount of aerosols. Furthermore, the presence of aerosols above clouds can also affect the accuracy of cloud property retrievals performed from satellite passive sensors, which in turn may perturb the estimation of the aerosol indirect effect (Haywood et al., 2004).

The detection of aerosols in cloudy scenes constitutes a new field of research in remote sensing. For passive remote sensing techniques, using total radiance measurements, the challenge is to derive the aerosol contribution while the cloud contribution is much larger. Innovative methods based on the use of spectral radiance measurements have, however, been developed and evaluated for some case studies. The approach described in De Graaf et al. (2007) uses measurements provided by the SCanning Imaging Absorption spectroMeter for Atmospheric CartograpHY (SCIAMACHY) instrument in a continuous broad spectral range $(0.28-1.75 \mu \mathrm{m})$ to estimate the AOT and the aerosol SSA, under some assumptions made on the aerosol and cloud microphysical and optical properties. The method described by Torres et al. (2012) uses measurements provided by the Ozone Monitoring Instrument (OMI) radiometer in two ultraviolet (UV) channels to simultaneously retrieve the aerosol and cloud optical thicknesses. Both methods require assumptions on the microphysical properties of the particles. Before retrieving the AOT, the two methods rely on the use of an aerosol index to qualitatively detect the presence of UV-absorbing aerosols in cloudy scenes. A method that allows detecting the height of absorbing aerosol layers present above clouds was also recently developed using absorbing aerosol index data and oxygen A band measurements provided by the Global Ozone Monitoring Experiment (GOME-2) instrument (Wang et al., 2012).

Active remote sensing techniques, based on the use of lidar systems, allow characterizing the vertical profile of the atmosphere (Winker et al., 2004). However, these instruments have limited spatial coverage, which is a clear disadvantage compared to passive sensors in terms of sampling events when aerosol layers are above clouds. Furthermore, current spaceborne lidar systems have limited capabilities to retrieve the aerosol burden without some priori knowledge on aerosol microphysics (Ackermann, 1998; Cattrall et al., 2005). An alternative method was recently developed for the Cloud-Aerosol Lidar with Orthogonal Polarization (CALIOP) spaceborne lidar that allows retrieving the optical thickness of any transparent layer (cirrus or aerosol) located above an opaque liquid water cloud. This method combines lidar backscattering coefficient measurements with linear depolarization ratio measurements and does not require assumptions on the aerosol microphysical properties (Hu et al., 2007).

Satellite passive remote sensing with polarization capabilities constitutes an alternative tool to study aerosols above clouds. In a general way, spectral angular polarized measurements are sensitive to particle loading, size, shape and composition via sensitivity to the real part of the refractive index (Mishchenko and Travis, 1997). The presence of aerosols above clouds significantly affects the polarized radiation reflected back to space by the cloud, as shown by the measurements provided by the POlarization and Directionality of Earth Reflectances (POLDER) instrument (Waquet et al., 2009a). An approximate formulation of the cloud-aerosol radiative interaction was developed using single scattering approximation. The method was used to estimate the AOT of a biomass-burning aerosol layer originated from South Africa and transported above stratiform low-level clouds in the South Atlantic Ocean. More recent works also outlined the importance of polarization measurements for the retrieval of the aerosol properties in cloudy scenes. Hasekamp (2010) analyzed the contribution of multi-spectral, multi-angular total and polarized radiance measurements for the purpose of the simultaneous retrieval of the aerosol and cloud properties. Their study investigated various types of aerosolcloud-contaminated scenes (AAC scenes and scenes with fractional cloud cover mixed with aerosols). Knobelspiesse et al. (2011) analyzed the sensitivity of polarization measurements to aerosol properties for AAC scenes using the airborne version of the Aerosol Polarimetry Sensor (APS) instrument. An example of the aerosol optical and microphysical property retrievals is presented in Knobelspiesse et al. (2011), where the case study is relative to a layer of anthropogenic particles suspended above a marine stratocumulus cloud in the Gulf of Mexico.

POLDER aboard Polarization and Anisotropy of Reflectances for Atmospheric Sciences Coupled with Observations from Lidar (PARASOL) was a part of the train of satellites called A-train. Between March 2006 and Dedember 2009 it acquired data in conjunction with multiple other passive and active sensors. We present a new operational algorithm that allows retrieving the properties of any aerosol layer (mineral dust particles or biomass-burning aerosols) 
transported above clouds using the polarization measurements provided by POLDER. We study the particle properties observed for different transport events of mineral dust particles and biomass-burning aerosols over cloudy scenes and cloud-free ocean scenes using data provided by the POLDER, MODIS (Salomonson et al., 1989) and CALIOP (Winker et al., 2004) instruments. We evaluate the different methods used to model the POLDER signal and to retrieve the particle properties. The strengths and limitations of each method are pointed out. The properties of the aerosols and clouds observed for various AAC scenes are provided. Limitations and uncertainties are summarized in the conclusion.

\section{Background and methods}

\subsection{Motivations}

Waquet et al. (2009a) developed a method that allows retrieving the AOT above clouds using polarized measurements. A global processing of one year of POLDER data was performed. The analysis of the results pointed out that the method was not able to accurately retrieve the AOT when mineral dust particles were present above clouds. Indeed, the AOTs were underestimated (by a factor 2 or 3 ) compared to the retrieval performed over the nearby clear-sky ocean pixels using the standard POLDER aerosol algorithm (Herman et al., 2005). The reason was that the method developed by Waquet et al. (2009a) was restricted to the use of observations acquired for scattering angles around 90-120 ${ }^{\circ}$ where polarization measurements are highly sensitive to scattering by fine-mode aerosols and only weakly sensitive to cloud microphysics. Since non-spherical particles, such as mineral dust particles, do not much polarize light in the selected scattering angle range, it led the algorithm to systematically underestimate the AOT by ignoring the contribution of the coarse mode. The lack of sensitivity of this method to mineral dust particles is the main motivation for the development of a new retrieval method able to retrieve the properties of any type of particles lofted above liquid water clouds. To a lesser extent, this shortcoming was also due to the use of an approximate modeling of the polarized reflectance.

Mineral dust particles do not much polarize light at forward scattering angles, but they strongly reduce the magnitude of the polarized cloud bow produced by liquid clouds underneath. The polarized cloud bow is a feature of liquid water clouds that corresponds to an intense and highly directional peak. Figure 1d shows the angular polarized features typically observed for liquid clouds in pristine conditions. The cloud bow is observed around a scattering angle of $140^{\circ}$. If aerosols are overlying liquid clouds, they attenuate the cloud bow, and this attenuation is directly related to the total optical thickness of the aerosol layer. The peculiar signature obtained for AAC scenes with biomass-burning aerosols and mineral dust particles are respectively shown in
Fig. 1a and b. For AAC scenes, an additional polarization signal at side scattering angles (scattering angles smaller than $130^{\circ}$ ) at 0.865 and $0.67 \mu \mathrm{m}$ and a spectral attenuation of the cloud bow magnitude at $140^{\circ}$ are observed that can be revelant to the particle type. Indeed, the attenuation of the primary cloud bow is spectrally dependent (i.e. colourful) for biomass-burning AAC and almost spectrally neutral for mineral dust particles between 0.67 and $0.865 \mu \mathrm{m}$. For the case presented, the primary bow is strongly attenuated but can still be observed around $140^{\circ}$ (see Fig. 1b), which indicates that a large amount of coarse-mode particles was transported above the clouds. We note also that the excess of polarization is much larger for biomass-burning aerosols than for mineral dust particles, particularly for 0.67 and $0.865 \mu \mathrm{m}$.

With respect to Waquet et al. (2009a), we hereinafter provide more accurate calculations of the polarized radiances and propose a new approach to retrieve the mineral dust AOT. In addition, we use the polarized measurements acquired in the cloud bow directions to improve the retrieval of both the biomass-burning aerosol properties and the cloud microphysical properties.

\subsection{Retrieval methods}

First, a "research algorithm" that uses all the available polarization measurements provided by the POLDER instrument was developed in order to parameterize a non-spherical aerosol particle model and to evaluate the potential of the POLDER polarization measurements for the simultaneous retrieval of the aerosol and cloud microphysical properties. Indeed, the cloud droplet distribution effective radius primarily controls the magnitude of the cloud bow for a single-layer cloud (Bréon et Goloub, 1998). A cloud particle model and an aerosol model therefore must be determined to analyze the POLDER data acquired for AAC scenes. We used also this research algorithm to perform a sensitivity study analysis, which is presented in Sect. 5.

A second algorithm was developed for reducing time computations. It is referred to hereafter as the "operational algorithm" and uses a specific strategy to incorporate the observations acquired in the cloud bow as well as auxiliary MODIS and POLDER cloud products to retrieve the AOT and the Ångström exponent above clouds at a global scale. Note that the two algorithms are connected since the research algorithm is first used to define the mineral dust particle model that is used in the operational algorithm in a second step.

The next section is dedicated to the description of both algorithms, including the description of the particle models and radiative transfer codes, used to accurately compute the polarized radiances. We present also a study concerning the 3 -D radiative cloud effects that may impact polarization reflectance magnitude in the cloud bow. 

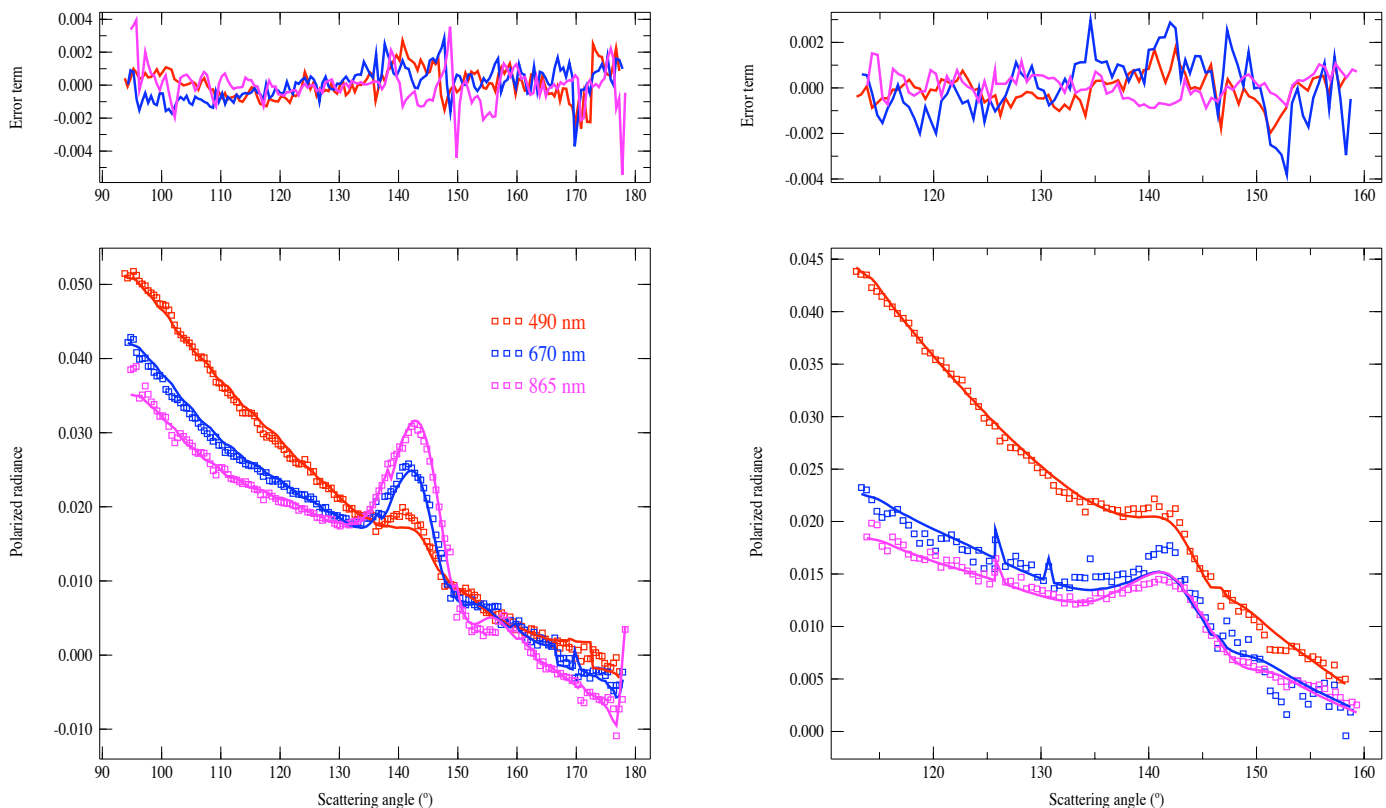

(a)
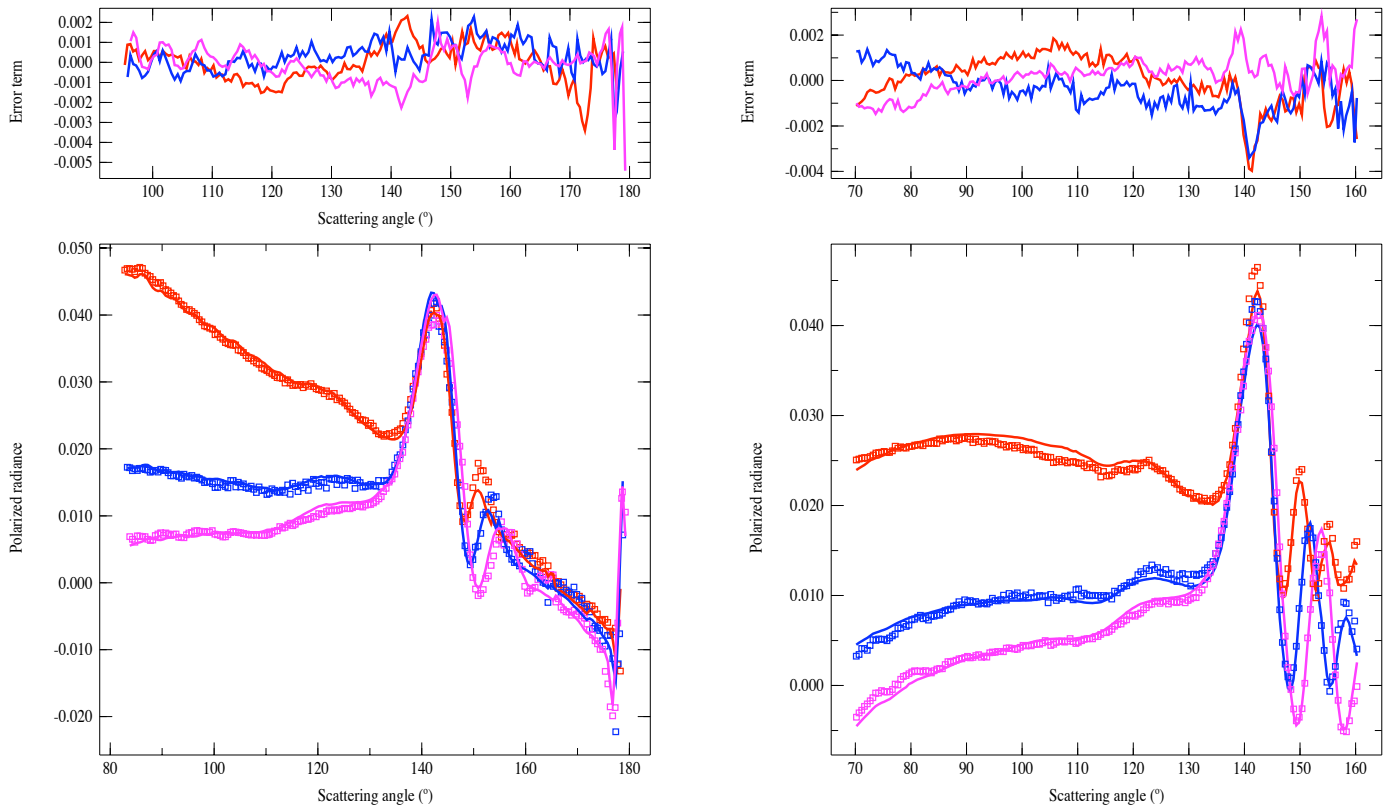

(c)

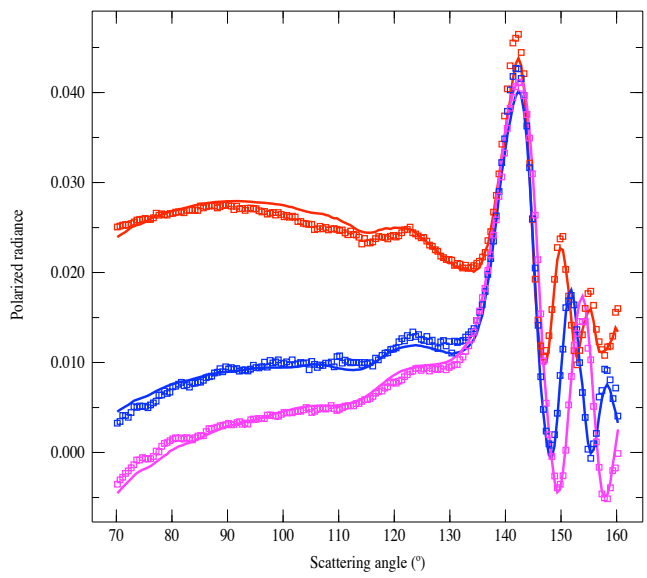

(d)

Fig. 1. Simulated and measured polarized radiance for various cases: (a) biomass-burning aerosols above clouds, (b) mineral dust aerosol above clouds, (c) few biomass-burning particles above clouds and (d) only liquid clouds far away from the sources of aerosols. The red, blue and magenta lines are the simulations performed at $0.49,0.67$ and $0.865 \mu \mathrm{m}$, respectively, whereas the dots are the measurements. The upper figures show the absolute differences between measured and simulated polarized radiances. The measured polarized radiances are aggregated at a spatial scale of $200 \times 200 \mathrm{~km}^{2}$ (i.e. hyper-pixel). The hyper-pixel shown in Fig. 1a-c corresponds respectively to box 1 in Fig. $6 a$, to box 3 in Fig. 8a, and to box 2 in Fig. 6a; the hyper-pixel (d) corresponds to an area located far away from continental sources of aerosols with only liquid clouds (not shown). The aerosol and cloud parameters retrieved for each hyper-pixel are given in Table 5. 
Table 1. A priori knowledge of the aerosol and cloud parameters $(f=$ fine mode, $c=$ coarse mode, cld $=$ cloud $)$ and associated uncertainties () .

\begin{tabular}{|c|c|c|c|c|c|c|c|c|c|c|}
\hline Parameters & $\tau_{\mathrm{f}}$ & $\tau_{\mathrm{c}}$ & $\begin{array}{c}r_{\mathrm{g}, \mathrm{f}} \\
(\mu \mathrm{m}) \\
\sigma_{\mathrm{f}}\end{array}$ & $\begin{array}{c}r_{\mathrm{g}, \mathrm{c}} \\
(\mu \mathrm{m}) \\
\sigma_{\mathrm{c}}\end{array}$ & $m_{\mathrm{r}}$ & $m_{i}$ & $\begin{array}{l}\text { Shape } \\
\text { (SF) }\end{array}$ & $\begin{array}{c}r_{\text {eff,cld }} \\
(\mu \mathrm{m})\end{array}$ & $v_{\text {eff,cld }}$ & $\begin{array}{l}m_{\mathrm{r}, \mathrm{cld}} \\
865 \mathrm{~nm} \\
670 \mathrm{~nm} \\
490 \mathrm{~nm}\end{array}$ \\
\hline $\begin{array}{l}\text { A priori } \\
\text { information }\end{array}$ & $\begin{array}{l}5 \times 10^{-3} \\
(+\infty)\end{array}$ & $\begin{array}{l}10^{-3} \\
(+\infty)\end{array}$ & $\begin{array}{c}0.15 \\
(0.1) \\
0.4 \\
(0.2)\end{array}$ & $\begin{array}{c}0.8 \\
(0.1) \\
0.6 \\
(0.3)\end{array}$ & $\begin{array}{c}1.47 \\
(0.14)\end{array}$ & $\begin{array}{l}10^{-3} \\
(0.1)\end{array}$ & $\begin{array}{c}0.5 \\
(0.5)\end{array}$ & $\begin{array}{c}10.0 \\
(10.0)\end{array}$ & $\begin{array}{c}0.06 \\
(0.06)\end{array}$ & $\begin{array}{l}1.330 \\
(0.01) \\
1.331 \\
(0.01) \\
1.338 \\
(0.01)\end{array}$ \\
\hline
\end{tabular}

\subsubsection{Simultaneous retrieval of the aerosol and cloud properties: the research algorithm}

The simultaneous retrieval of aerosol and cloud properties is performed using an optimal estimation method (OEM), similar to the one described in Waquet et al. (2009b). The particle properties are retrieved by comparing the measured and simulated polarized radiances and by adjusting the parameters in the particle models until the best match is found. The search for the best solution is achieved through the use of an iterative process. We use the Newton-Gauss iteration modified with the Levenberg-Marquadt technique to ensure convergence. We refer to Waquet et al. (2009b) or to Rodgers (2000) for more details concerning the practical implementation of this procedure. The OEM is coupled with a radiative transfer code and a module that allows calculating the optical properties of the particles (described hereafter). This method provides a diagnostic error that accounts for the measurements' sensitivity to the retrieved parameters, the measurement errors and the modeling errors as well as any available a priori information. The retrieval error covariance matrix $\mathbf{C}_{x}$ is defined as

$\mathbf{C}_{x}=\left(\mathbf{C}_{\mathrm{a}}^{-1}+\mathbf{K}^{T} \cdot \mathbf{C}_{\mathrm{T}}^{-1} \cdot \mathbf{K}\right)^{-1}$,

where $\mathbf{C}_{\mathrm{T}}$ is the total error covariance matrix and $\mathbf{C}_{\mathrm{a}}$ is the a priori error covariance matrix. $\mathbf{K}$ is the Jacobian matrix and its $i$-th row and $j$-th column element is defined as

$\mathbf{K}_{i j}(\boldsymbol{X})=\frac{\partial \boldsymbol{F}_{i}(\boldsymbol{X})}{\partial \boldsymbol{X}_{j}}$,

where $\boldsymbol{F}$ is the simulation vector and $\boldsymbol{X}$ is the vector of parameters. $\mathbf{K}$ is computed for each observation $(i)$ and each parameter $(j)$ and represents the sensitivity of the simulated polarized radiances to the particle parameters.

The square root of the diagonal elements of the error covariance matrix provides the standard deviation associated with each retrieved parameter. The error covariance matrices for the optical parameters are derived from the retrieved parameters and computed using Eq. (1) and the formula given in Appendix (Eq. A1).

\subsubsection{Particle models and a priori information}

A combination of two lognormal size distribution functions (accumulation and coarse modes) is assumed for the aerosols. A geometric mean radius and a standard deviation are used to describe each lognormal function $\left(r_{\mathrm{g}}\right.$ and $\left.\sigma\right)$. The other aerosol parameters considered in the particle models are the column number density of particles $\left(N\right.$, in $\left.\mu^{-2}\right)$ for both modes and the complex refractive index $\left(m_{\mathrm{r}}-m_{i} i\right)$ that is assumed to be spectrally invariant and the same for both modes. The effective radius, $r_{\text {eff }}$, is related to the lognormal size distribution parameters using the formula given in Appendix (Eq. A2). As shown later, the polarization measurements provided by the POLDER instrument do not contain enough information to retrieve all the aerosol parameters previously listed. A sensitivity study analysis presented in Sect. 5 is used to determine the retrieval option (number of retrieved parameters) that is finally preferred to retrieve the aerosol properties in function of the type of AAC scenes (i.e. biomass-burning aerosols or mineral dust particles above clouds).

For aerosols, we consider a mixture of spherical and non-spherical particles. Non-spherical particles are spheroid models with various aspect ratios (Mishchenko and Travis, 1994; Dubovik et al., 2006). The aspect ratio distribution model is the one derived by Dubovik et al. (2006) from the analysis of the scattering matrix of mineral dust samples (Volten et al., 2001). The ratio of spherical particles over the total number of particles, i.e. the spherical fraction (SF), is included in the retrieval process for AAC scenes with mineral dust particles.

The cloud droplet size distribution is assumed to follow a gamma standard law, described by the same two parameters - the cloud droplet effective radius, $r_{\text {eff,cld }}$, and the cloud droplet effective variance, $v_{\text {eff,cld }}-$ as defined in Hansen and Travis (1974). Angular polarization measurements are highly sensitive to the real refractive index of large spherical particles due to the presence of bows. We make clear that the droplet real refractive index is primarily included in the retrieval process to ensure an accurate modeling of the cloud bows (angular locations and magnitudes). The real refractive 
Table 2. Cloud parameters retrieved by POLDER and MODIS using different standard algorithms to select the scene for the operational algorithm developed for AAC scenes.

\begin{tabular}{|c|c|c|c|}
\hline Symbol & Description & Measurements and method & $\begin{array}{l}\text { Product affiliation } \\
\text { (when available) }\end{array}$ \\
\hline $\begin{array}{l}\mathrm{COT} \\
(\triangle \mathrm{COD})\end{array}$ & $\begin{array}{l}\text { Mean cloud optical } \\
\text { thickness and associated } \\
\text { standard deviation }\end{array}$ & \multirow{2}{*}{$\begin{array}{l}\text { MODIS total radiance } \\
\text { measurements acquired at } 0.865 \\
\text { and } 2.13 \mu \mathrm{m} \text { (Platnick et al., } \\
\text { 2003) }\end{array}$} & \multirow{2}{*}{$\begin{array}{l}\text { Level-2 MODIS06 } \\
\text { cloud product given at } \\
\text { pixel resolution of } 1 \times 1 \\
\mathrm{~km}^{2} \text { (Platnick et al., } \\
2003 \text { ) }\end{array}$} \\
\hline $\begin{array}{l}\text { REFF_CLD_M } \\
(\Delta \text { REFF_CLD_M })\end{array}$ & $\begin{array}{l}\text { Mean cloud droplet } \\
\text { effective radius and } \\
\text { associated standard } \\
\text { deviation }(\mu \mathrm{m})\end{array}$ & & \\
\hline$z_{\mathrm{c}-\text { Rayleigh }}$ & $\begin{array}{l}\text { Cloud top height (1) } \\
(\mathrm{km})\end{array}$ & $\begin{array}{l}\text { Rayleigh cloud top pressure } \\
\text { method: POLDER polarization } \\
\text { signal of the molecules located } \\
\text { above the clouds (Goloub et al., } \\
\text { 1994; Parol et al., 2004) }\end{array}$ & \multirow[t]{2}{*}{$\begin{array}{l}\text { RB2 (radiative budget } \\
\text { level 2) cloud products } \\
\text { given at pixel resolution } \\
\text { of } 18.5 \mathrm{~km} \times 18.5 \mathrm{~km}\end{array}$} \\
\hline$z_{\mathrm{c}-} \mathrm{O}_{2}$ & $\begin{array}{l}\text { Cloud top height (2) } \\
(\mathrm{km})\end{array}$ & $\begin{array}{l}\text { Apparent } \mathrm{O}_{2} \text { cloud pressure } \\
\text { method: differential absorption } \\
\text { measurements in the oxygen } \\
\text { A-band of POLDER (Vanbauce } \\
\text { et al., 2003) }\end{array}$ & \\
\hline$z_{\mathrm{c}-\mathrm{IR}}$ & $\begin{array}{l}\text { Cloud top height (3) } \\
(\mathrm{km})\end{array}$ & $\begin{array}{l}\text { IR cloud top pressure method: } \\
\text { MODIS measurements acquired } \\
\text { in the thermal infrared (Menzel } \\
\text { et al., 2010) }\end{array}$ & $\begin{array}{l}\text { MYD06 cloud product } \\
\text { that provides data at a } \\
\text { resolution of } 5 \mathrm{~km} \times 5 \mathrm{~km} \\
\text { (Platnick et al., 2003) }\end{array}$ \\
\hline phase_index & $\begin{array}{l}\text { Cloud thermodynamic } \\
\text { phase index ranging from } \\
\text { confident liquid phase } \\
\text { only to confident ice } \\
\text { only }(0<\text { phase_index }<200) \text {. }\end{array}$ & $\begin{array}{l}\text { POLDER polarization } \\
\text { measurements combined with } \\
\text { MODIS measurements acquired } \\
\text { in the solar spectrum and } \\
\text { thermal infrared (Riedi et al., } \\
\text { 2010) }\end{array}$ & $\begin{array}{l}\text { PM-L2.v1.00 cloud } \\
\text { products that provide } \\
\text { data at } 6 \mathrm{~km} \times 6 \mathrm{~km} \\
\text { available from } \\
\text { icare.univ-lille1.fr }\end{array}$ \\
\hline
\end{tabular}

index for cloud droplets, $m_{\mathrm{r}, \mathrm{cld}}$, is then retrieved in each spectral band. The imaginary refractive index for cloud droplets is less than $5 \times 10^{-7}$ for the POLDER wavelengths (Hale and Querry, 1973) and is therefore neglected and held constant to 0 in the calculations. The droplet effective variance is also included in the algorithm, since this parameter strongly impacts the magnitude of supernumerary cloud bows. The cloud droplets are modeled as spheres and their optical properties are therefore calculated using the Mie theory.

In Table 1, we provide the values of the a priori aerosol and cloud parameters ("starting point for $\boldsymbol{X}$ ") and the associated uncertainties $\left(\mathbf{C}_{\mathrm{a}}\right)$. The subscripts $\mathrm{f}$ and c respectively denote parameters that describe the fine-mode and coarsemode aerosols. The number of retrieved parameters included in the OEM can be modified, and the a priori information as well. If so, the corresponding information is provided in the text.

\subsubsection{Forward model}

\section{(a) Radiative transfer code and particle vertical distribution}

The polarized radiances are computed using the successive order of scattering (SOS) code that accounts for the effects of multiple scattering under the assumption of the plane parallel atmosphere (Lenoble et al., 2007). The SOS code provides the usual three first Stokes parameters and allows including various atmospheric components that are separately described for the optical properties and the vertical profile. The vertical profile for the molecules is defined using a decreasing exponential law with a scale height of $8 \mathrm{~km}$. The molecular optical thickness and the effects of molecular anisotropy are computed using the formulae given in Hansen and Travis (1974). The vertical profile of the aerosol layer is described using a Gaussian distribution function, defined by a standard deviation (0.75) and a mean altitude value, $z$ mean. The cloud droplets are assumed well 

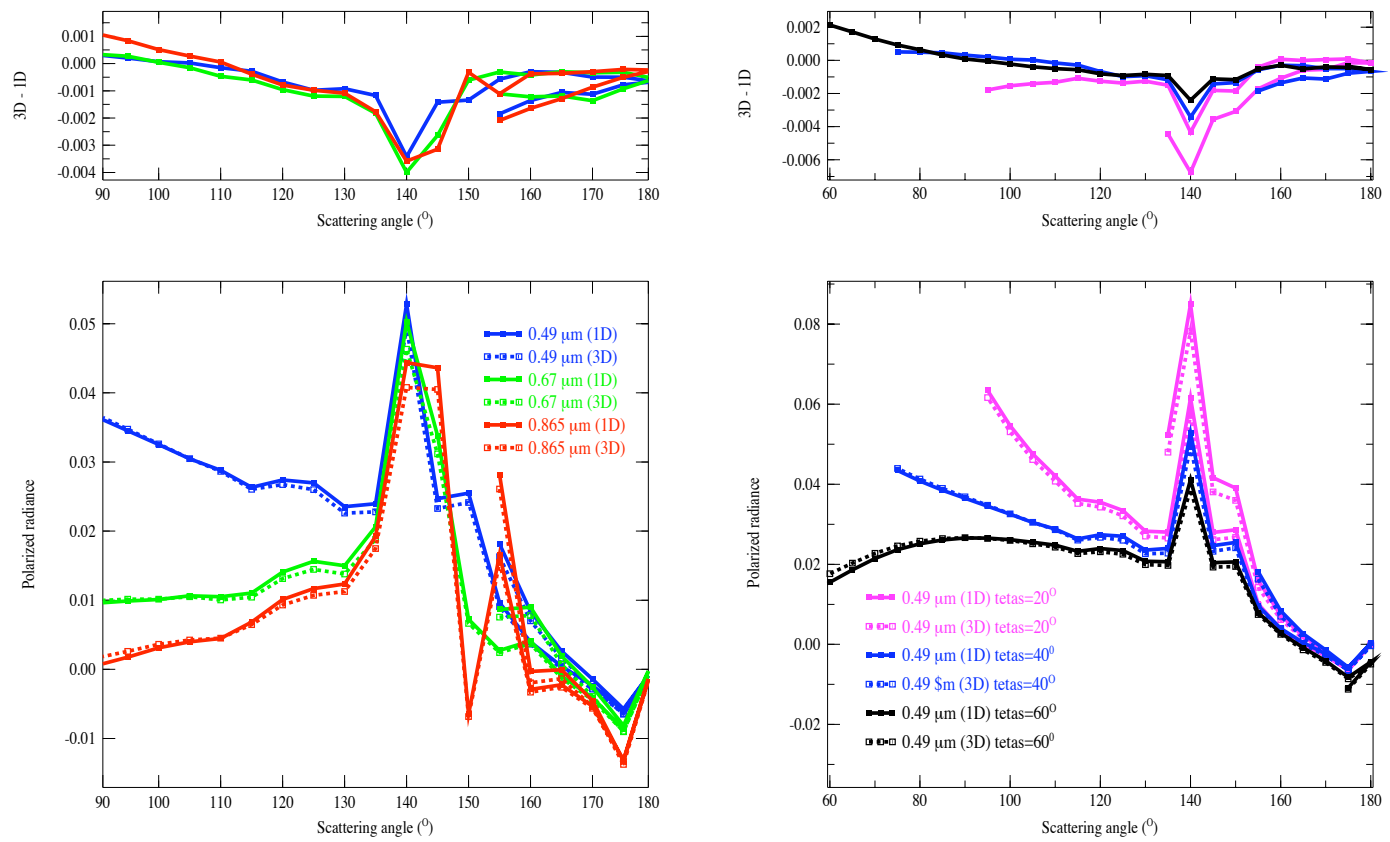

(a)

(b)

Fig. 2. (a) 1-D vs. 3-D simulations of the polarized radiance for a liquid cloud for 3 wavelengths and (b) 3 different sun angles. Dashed lines for 3-D calculations and solid lines for 1-D calculations. The red, green and blue lines in (a) correspond to the wavelengths $0.865,0.670$ and $0.490 \mu \mathrm{m}$, respectively, and a sun zenithal angle of $40^{\circ}$, whereas the magenta, blue and black lines in (b) correspond to sun zenithal angles of 20,40 and $60^{\circ}$, respectively, and to the wavelength $0.49 \mu \mathrm{m}$. The absolute differences between the 3-D and 1-D calculations are shown in the upper figures.

mixed with the molecules between the surface and the cloud top height. The cloud base height is therefore supposed to be at $0 \mathrm{~km}$. For case studies analysis, the mean altitude of the aerosol layer and the cloud top height are adjusted using the lidar data. When those are not available, we use the "apparent $\mathrm{O}_{2}$ cloud pressure" to estimate the cloud top height $\left(z_{\mathrm{c}-} \mathrm{O}_{2}\right.$, see Table 2$)$ and assume a mean altitude of $3.5 \mathrm{~km}$ for the AAC height. An empirical correction on $z_{\mathrm{c}-} \mathrm{O}_{2}$ accounts for the underestimate of the apparent $\mathrm{O}_{2}$ cloud pressure method when compared to the lidar. The cloud optical thickness is held constant to 5, which ensures that the polarized radiance reflected by the cloud layer is saturated and does not depend on it. A truncation procedure of the forward scattering peak is implemented in the SOS code, which allows a faster modeling of the radiances. The radiances are therefore calculated using a truncated phase function since the errors induced by this approximation are small (see Appendix A4).

\section{(b) 3-D cloud effects}

It is well known that the homogeneous 1-D cloud assumption leads to errors in the retrieved cloud parameters from total visible radiance (Marshak and Davis, 2005). Cornet et al. (2010) show for a cirrus cloud with a MonteCarlo radiative transfer code that biases exist also on polarized radiance. To assess the errors in our 1-D radiative transfer model, we compute $3-\mathrm{D}$ and $1-\mathrm{D}$ polarized radiance of a stratocumulus cloud with a mean optical thickness of 10 , a uniform effective radius of $10 \mu \mathrm{m}$ and an effective variance of 0.02 . The heterogeneity parameter is 7 for the optical thickness (standard deviation associated with the mean optical thickness). The initial resolution of the radiative transfer simulation is $80 \times 80 \mathrm{~m}^{2}$. The radiances are then spatially averaged at $10 \times 10 \mathrm{~km}^{2}$ to simulate the observation of a sensor like POLDER. The differences between the 1-D and 3-D polarized reflectances as a function of scattering angle are presented in Fig. 2 for the three wavelengths used in the algorithm and for different sun angles. For most of the scattering angles, and for the case considered here, which does not include microphysical heterogeneity, the differences between the two polarized reflectances are small and within the statistical error of the Monte-Carlo simulations (not plotted). Exceptions appear, however, in the forward direction for large sun angle and in the cloud bow regions near $140^{\circ}$, where the $1-\mathrm{D}$ simulations systematically overestimate the ones that account for the 3 -D cloud effects by about 5-8\%, depending on wavelength and geometry $\left(\theta_{\mathrm{s}}, \phi\right)$. For computional cost considerations, it is practically impossible to account for those 3-D effects in our retrieval procedure, so we incorporated these errors in 


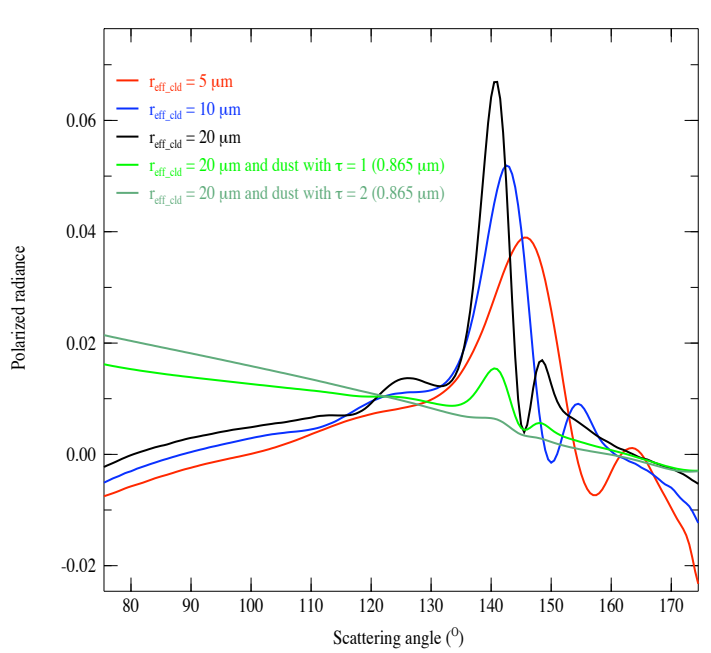

Fig. 3. Polarized radiances simulated at $0.865 \mu \mathrm{m}$ for liquid clouds as a function of the scattering angle. Three droplet effective radii are considered $\left(r_{\text {eff,cld }}=5,10\right.$ and $\left.20 \mu \mathrm{m}\right)$. In green, additional simulations performed with mineral dust particles suspended above liquid clouds for two aerosol optical thicknesses ( $\tau=1$ and 2). The droplet effective radius of the cloud layer located below the aerosol layer is equal to $20 \mu \mathrm{m}$, and the cloud optical thickness is equal to 5 for all calculations.

the cloud bow regions into the total error covariance matrix $\left(\mathbf{C}_{\mathrm{T}}\right)$.

\subsubsection{The operational algorithm}

A look-up table (LUT) approach is needed to derive the aerosol properties above clouds at a large scale. The number of retrieved parameters is then reduced to the AOT, the Angström exponent and the cloud droplet effective radius. The effects of the droplet effective radius and AOT are illustrated in Fig. 3. To build the LUT, we calculate the polarized radiances using the SOS code for different combinations of aerosol and cloud particle models. We consider six accumulation modes for aerosol models $\left(r_{\mathrm{g}, \mathrm{f}}=0.06\right.$, $0.08,0.10,0.12,0.14,0.16 \mu \mathrm{m}$ and $\left.\sigma_{\mathrm{f}}=0.4\right)$ with a constant complex refractive index of $1.47-0.01 i$, which is a mean value for polluted and biomass-burning aerosols. We also included the mineral dust particle model derived using the research algorithm (see Table 5, case 4). The elements of the polarized phase function were shown for similar particle models in previous studies (e.g. see Figs. 1 and 2 in Waquet et al., 2007). The polarized radiances are calculated for various AOTs and viewing geometries, then interpolation processes are considered. For cloud particles, we consider 22 droplet models with effective radius varying between 5 and $26 \mu \mathrm{m}$ by step of $1 \mu \mathrm{m}$, with a constant droplet variance of $v_{\text {eff,cld }}=0.06$ and a constant real refractive index of $m_{\mathrm{r}, \mathrm{cld}}(0.490 \mu \mathrm{m})=1.338, m_{\mathrm{r}, \mathrm{cld}}(0.670 \mu \mathrm{m})=1.331$ and $\left.m_{\mathrm{r}, \mathrm{cld}}(0.865 \mu \mathrm{m})=1.330\right)$. We assume a cloud top height of $0.75 \mathrm{~km}$ and a value of $3.5 \mathrm{~km}$ for the aerosol layer mean altitude. POLDER provides polarized radiance measurements at $0.49,0.67$ and $0.865 \mu \mathrm{m}$ (see Sect. 3.1). The effects of the atmospheric vertical profile on the measured polarized signal are very limited at $0.67 \mu \mathrm{m}$ and almost negligible at $0.865 \mu \mathrm{m}$ compared to $0.49 \mu \mathrm{m}$, and we therefore restrict the operational algorithm to these two longer wavelengths.

A schematic view of the algorithm is shown in Fig. 4. A different retrieval strategy is considered depending on the aerosol type and load. We first estimate the AOT above clouds by using all available angular information and by only considering the six fine-mode particle models. If the retrieved AOT is larger than 0.1 at $0.865 \mu \mathrm{m}$, we then compare the least square error term (see Appendix, Eq. A3) computed for the mineral dust particle model with ones computed for the six other fine-mode particle models and keep the solution obtained with the mineral dust model if this latter model minimizes the error term. The threshold of 0.1 in AOT is justified because the retrieval of the dust AOT becomes difficult (instable) when AAC optical thickness becomes small. This is probably due to the 3-D radiative transfer effects that render difficult the modeling of the primary cloud bow when the atmosphere above clouds is pristine. If the AOT retrieved at the first step is smaller than 0.1 or if the mineral dust particle model fails to reproduce data, we then only consider the six fine-mode particle models and restrict the algorithm to observations acquired at scattering angles smaller than $130^{\circ}$ since the inclusion of the data acquired in the polarized cloud bow is not critical for the retrieval of the finemode AOT. The retrieval strategy also incorporates the fact that the POLDER instrument sometimes does not observe the side scattering and forward scattering geometries (data for $\Theta<130^{\circ}$ unavailable).

The droplet effective radius can be derived as a part of the retrieval process or estimated using the one retrieved by MODIS. We compared both approaches and found only small differences in the retrieved AAC optical thickness. Differences observed between the cloud droplet effective radius retrieved from total radiance measurements and polarized measurements are generally small for AAC scenes (see Sect. 5.2.3), so both approaches lead to small differences in the retrieved AAC optical thickness. We then choose to use the MODIS droplet effective radius since its retrieval does not depend on the availability of a particular viewing geometry. The impacts of the 3-D effects on the retrieved AOT for dust particles were evaluated using synthetic data. We simulated polarized radiances for AAC scenes with mineral dust particles. We considered the mineral dust particle model implemented in the operational algorithm and an AOT of 1.04 at $0.865 \mu \mathrm{m}$. We decreased by $8 \%$ the magnitude of the synthetic polarized radiances in the cloud bow directions to evaluate the impacts on the AOT due to the uncertainties in modeling the cloud bow magnitude. We found that the algorithm then overestimates the true AOT by 0.06 (relative error of $6 \%$ ). Note that this source of error only affects the 

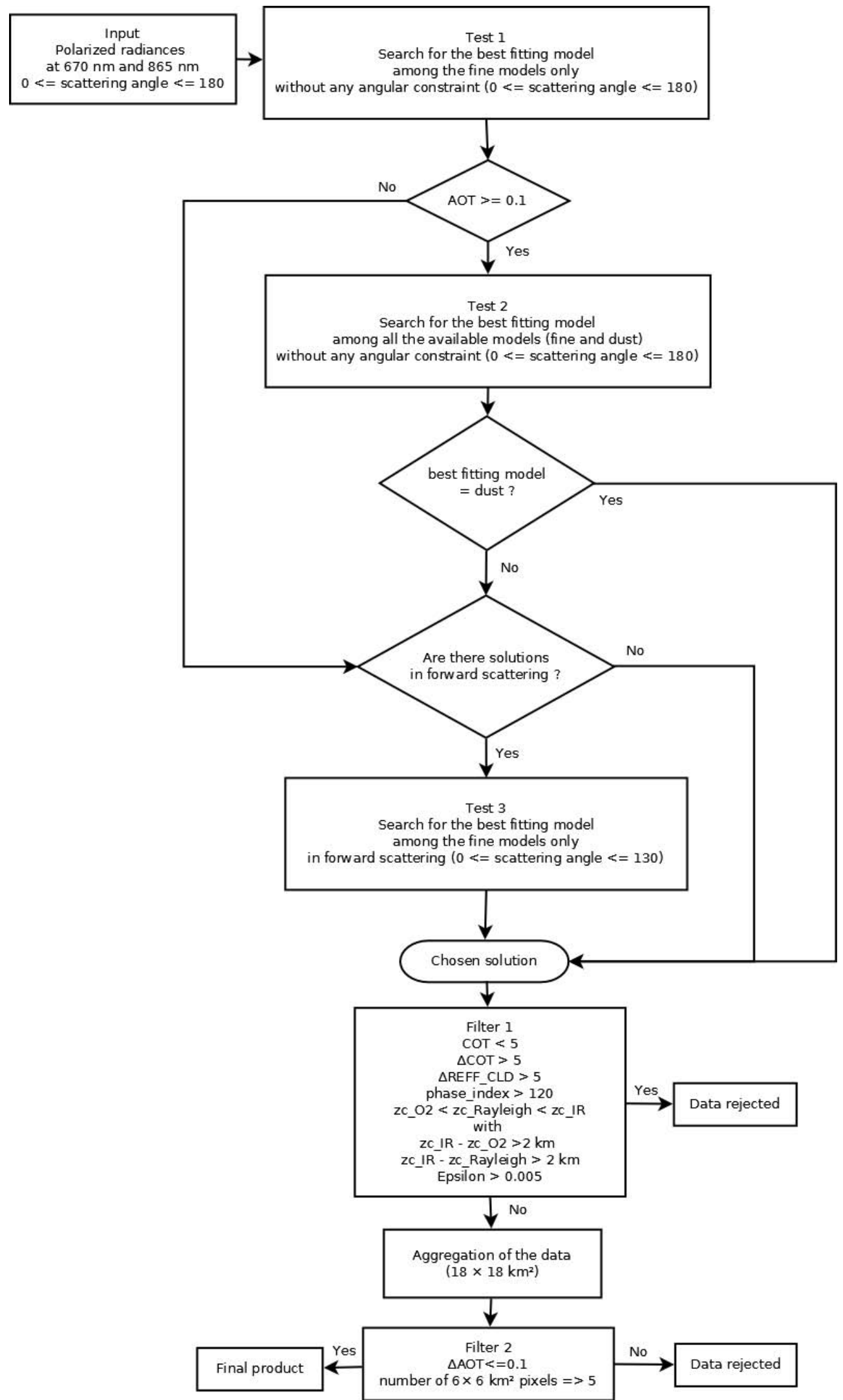

Fig. 4. Schematic view of the operational algorithm used to retrieve the aerosol properties above clouds at a global scale from POLDER polarization data acquired at 0.67 and $0.865 \mu \mathrm{m}$ and MODIS/POLDER combined cloud products. 
AOT retrieved for mineral dust particles since the measurements acquired in the cloud bow are not used for the retrieval of fine-mode particle properties, for which we only consider data acquired for scattering angles smaller than $130^{\circ}$.

Different filters are eventually applied to the data to obtain a quality-assessed product. For example, we only apply the operational algorithm to homogeneous cloudy pixels associated with optically thick liquid water clouds. The criteria and the cloud parameters used to select the cloudy scenes are given in Fig. 4. We refer to Sect. 3.4 and Table 2 for the description of the cloud parameters used. We also added a criterion that allows rejecting pixels for which the POLDER data are not accurately fitted (the least square error term $\varepsilon$ must be smaller than 0.005). The AOT is first retrieved at the finest spatial resolution of POLDER (i.e. $6 \times 6 \mathrm{~km}^{2}$ ) and finally aggregated at a spatial resolution of $18 \times 18 \mathrm{~km}^{2}$, and we only keep these pixels for which the AOT standard deviation $\left(\Delta \_\right.$AOT $)$is smaller than 0.1 and that contain more than four $6 \times 6 \mathrm{~km}^{2}$ pixels. This latter procedure allows rejecting the edges of the clouds where our retrieved AOT are generally doubtful and where the radiances should be not modeled with a plane parallel radiative transfer code.

\section{Observations}

\subsection{POLDER data}

The data provided by POLDER instrument are the normalized total and polarized radiances, $L$ and $L_{\mathrm{p}}$. The normalized total radiance $L$ is given by

$L=\frac{\pi L^{*}}{E_{\mathrm{s}}}$,

where $L^{*}$ is the spectral radiance $\left(\mathrm{W} \mathrm{m}^{-2} \mathrm{sr}^{-1} \mu \mathrm{m}^{-1}\right)$ and $E_{\mathrm{S}}$ is the spectral solar extraterrestrial irradiance $\left(\mathrm{W} \mathrm{m}^{-2} \mu \mathrm{m}^{-1}\right.$ ). The quantity $L^{*}$ is related to the first Stokes parameter I and describes the total radiance measured by the instrument. $L_{\mathrm{p}}$ is given by

$L_{\mathrm{p}}= \pm \frac{\pi \sqrt{\left(Q^{2}+U^{2}\right)}}{E_{\mathrm{s}}}$,

where $Q$ and $U$ are the second and third Stokes parameters that characterize the linear polarization state of light. The Stokes parameters have the dimension of a spectral radiance $\left(\mathrm{W} \mathrm{m}^{-2} \mathrm{sr}^{-1} \cdot \mu \mathrm{m}^{-1}\right)$. The plus or minus sign indicates that the direction of the scattered electric field is preferentially normal or parallel to the scattering plan (Herman et al., 2005). Throughout the paper, when we discuss radiances, we will be referring to these normalized quantities. The polarized radiances are measured in three spectral bands at 0.490 , 0.670 and $0.865 \mu \mathrm{m}$. The POLDER instrument also acquires total radiance measurements in a number of other spectral bands (e.g. 0.765 and $1.02 \mu \mathrm{m}$ ) and provides images of the scene being viewed on a CCD matrix camera. The spatial resolution of POLDER is equal to $5.3 \times 6.2 \mathrm{~km}^{2}$ at nadir. Because of the satellite motion and instrument design, the POLDER instrument can see the same scene from multiple angles (up to 16), allowing measuring the angular variability of these radiances. The viewing geometry is characterized by the scattering angle, $\Theta$, which is the angle formed between the incident and scattered directions. We also introduce the sun zenith angle, $\theta_{\mathrm{s}}$, the view angle, $\theta_{\mathrm{v}}$, and the relative azimuth angle, $\phi$.

\subsection{Errors' measurements}

The error budget in the measurements is taken from Fougnie et al. (2007) and used to fill out the total error covariance matrix. We consider a relative error of calibration of $2 \%$ in the three polarized spectral bands. The noise associated with the polarized radiances for cloudy scenes is estimated to be $2.5 \times 10^{-3}$ at 0.49 and $0.865 \mu \mathrm{m}$, and $5 \times 10^{-3}$ at $0.67 \mu \mathrm{m}$. We assume that the different sources of errors are independent and the total covariance matrix is given by the sum of the different error covariance matrices.

\subsection{Hyper-pixel data}

The research algorithm is used in Sect. 5 to evaluate the potential of the POLDER-aggregated data to simultaneously retrieve the aerosol and cloud microphysical properties for $\mathrm{AAC}$ scenes. It requires a homogeneous sampling of the scattering angles in order to retrieve the cloud particle microphysics (Bréon et Goloub, 1998). The results should also be more accurate when a high angular resolution is available. To obtain this required sampling, we use the so-called "hyperpixel", which refers to POLDER data aggregated at a spatial scale of $200 \times 200 \mathrm{~km}^{2}$. The specific procedure used for the aggregation of the data is different than the one used in Bréon and Goloub (1998), and it is described below.

Before the retrieval of the aerosol and cloud at the hyperpixel scale, we first apply a retrieval method that works at the finest spatial POLDER resolution $\left(6 \times 6 \mathrm{~km}^{2}\right)$, such as the one described in Waquet et al. (2009a). It allows estimating the spatial variability of the AOT above clouds within the hyper-pixel and selecting only homogeneous pixels in terms of both aerosol and cloud properties. The variability of the atmospheric vertical profile within the hyper-pixel is also qualitatively estimated using the apparent $\mathrm{O}_{2}$ cloud pressure and lidar data when available. Indeed, thin cirrus, multi-layers or broken-cloud situations tend to increase the spatial variability of the observed apparent $\mathrm{O}_{2}$ pressure.

Once having selected the homogeneous scenes, we come back to the data and split them using the polar coordinate system and subdivide the range of scattering sampled by POLDER into small intervals of $0.5^{\circ}$. A mean viewing geometry $\left(\overline{\theta_{\mathrm{s}}}, \overline{\theta_{\mathrm{v}}}, \bar{\phi}\right.$ and $\left.\bar{\Theta}\right)$ and a mean polarized radiance value are then computed for each $0.5^{\circ}$ scattering angle interval, using 


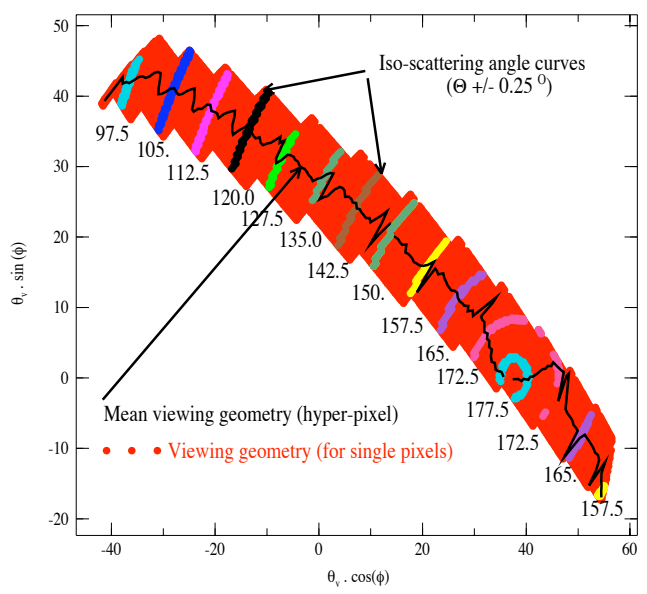

(a)

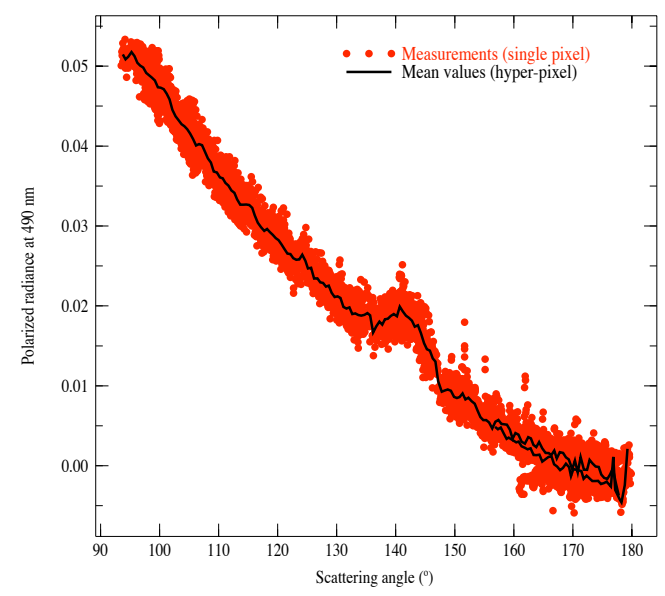

(b)

Fig. 5. (a) Viewing geometry represented in polar coordinates for each single pixel of $6 \mathrm{~km} \times 6 \mathrm{~km}$ (red dots) observed by POLDER within an area of $200 \times 200 \mathrm{~km}^{2}$ (the "hyper-pixel"). The mean viewing geometry for the hyper-pixel is the black line. (b) Polarized radiances measured for each single pixel (red dots) and mean polarized radiance for the hyper-pixel (black line).

the corresponding information available at the $6 \times 6 \mathrm{~km}^{2}$ spatial resolution. The scattering angle used to depict the angular behavior of the mean polarized radiance is referred to as $\overline{\Theta^{*}}$ and is computed from the mean viewing geometry $\left(\overline{\theta_{\mathrm{s}}}, \overline{\theta_{\mathrm{v}}}\right.$ and $\bar{\phi}$ ).

In addition, precautions must be taken for the calculation of the mean viewing geometry when the multiple scattering effects in the atmosphere have to be accounted for. The data associated with different viewing geometries $\left(\theta_{\mathrm{v}}, \phi\right)$ that correspond to the same value of scattering angle must be separately aggregated since these data show different values of polarized radiance, due to the effects of cloud multiple scattering. We apply a geometric criterion (i.e. $\left|\bar{\Theta}^{*}-\bar{\Theta}\right|<0.1^{\circ}$ ) that prevents aggregating together data belonging to the same $0.5^{\circ}$ scattering angle interval even though they are associated with significantly different viewing geometries.

An example of aggregated data is shown in Fig. 5. Two different "branches of scattering angle" are usually observed by POLDER when an area of $200 \times 200 \mathrm{~km}^{2}$ is considered (e.g. $97^{\circ}<\Theta<177^{\circ}$ and $157^{\circ}<\Theta<177^{\circ}$ in Fig. 5a). In the retrieval algorithm, we consider only one branch of scattering angle for the sake of simplicity. We select the branch associated with the widest range of scattering angles (e.g. $97^{\circ}<\Theta<177^{\circ}$ in Fig. 5a). Figure 5a and b show that this procedure allows obtaining rather smooth mean polarized radiances associated with a consistent mean viewing geometry.

\subsection{Aerosol and cloud properties from the A-TRAIN}

So far, our algorithm does not allow retrieving aerosols over cloud-free ocean. Therefore, we use the algorithm developed by Herman et al. (2005) to derive these aerosol properties over cloud-free ocean scenes. Total and polarization radiances acquired at 0.670 and $0.865 \mu \mathrm{m}$ to derive several aerosol parameters at a resolution of $18.5 \mathrm{~km} \times 18.5 \mathrm{~km}$ are used to derive mainly the aerosol optical thickness and the Ångström exponent, a parameter indicative of the particle size. The Ångström exponent is about 0.4 for mineral dust particles and typically larger than 1.8 for biomass-burning aerosols (Dubovik et al., 2002). The AOT for the fine and coarse modes can also be retrieved as well as the fraction of non-spherical particles within the coarse mode. This latter parameter is only retrieved when the geometrical conditions are favourable. We refer to Herman et al. (2005) for more details regarding the assumptions used for the particle models and the modeling of the radiances.

In our analysis, we also use collocated cloud properties retrieved from MODIS and POLDER to characterize the cloudy scenes. We take advantage of the high spatial resolution retrieval capabilities of MODIS $\left(1 \times 1 \mathrm{~km}^{2}\right.$ at nadir $)$ to estimate within each PARASOL pixel $\left(6 \times 6 \mathrm{~km}^{2}\right)$ the variability of the cloud properties. We compute a mean value for the cloud optical thickness (COT) and for the cloud droplet effective radius (REFF_CLD_M) as well as a standard deviation for each parameter ( $\Delta_{-}$COT and $\Delta \_$REFF_CLD). The POLDER and MODIS instruments also provide various estimates for the cloud top heights. The comparison of these estimates provides valuable information for the detection of multi-layer situations (Waquet et al., 2009a). In the following, we use the cloud top altitude retrieved with: (i) the "IR cloud top pressure" method $\left(z_{\mathrm{c}} \mathrm{IR}\right)$, (ii) the "Rayleigh cloud top pressure" method ( $z_{c}$ Rayleigh), and (iii) the apparent $\mathrm{O}_{2}$ cloud pressure method $\left(z_{\mathrm{c}-} \mathrm{O}_{2}\right)$. Cloud top pressure values were converted to cloud top heights using a fixed scale height. We also used the cloud phase, derived from a combination of POLDER and MODIS measurements, which is provided as a semi-continuous index, 


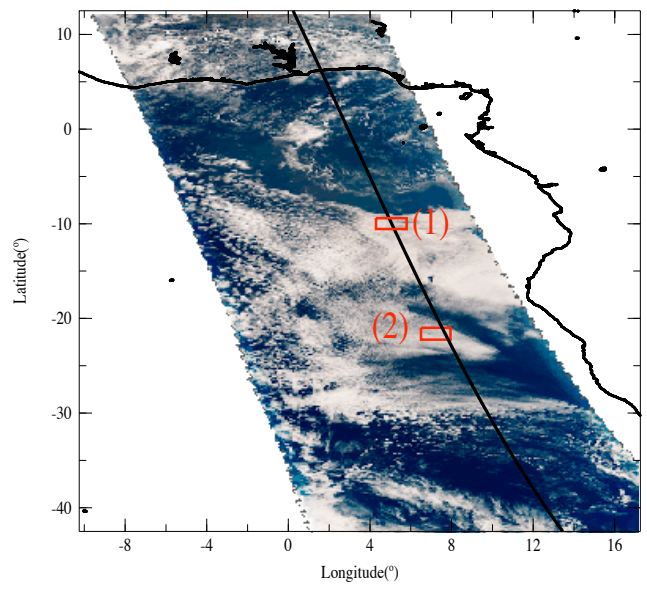

(a)

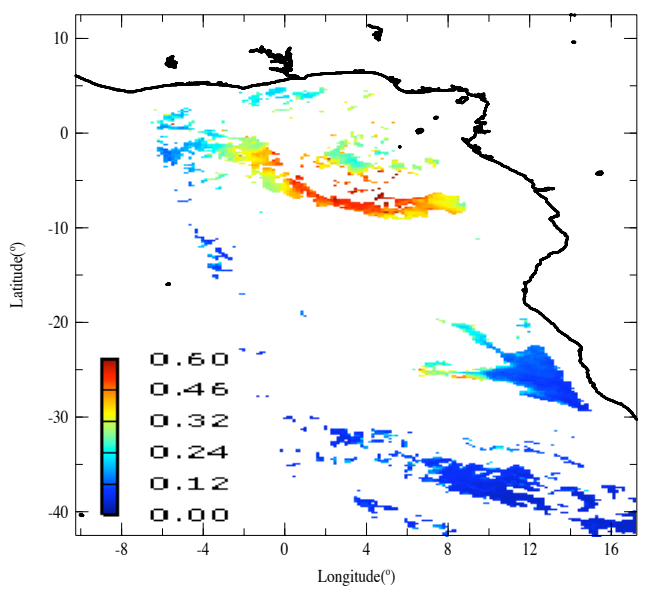

(b)

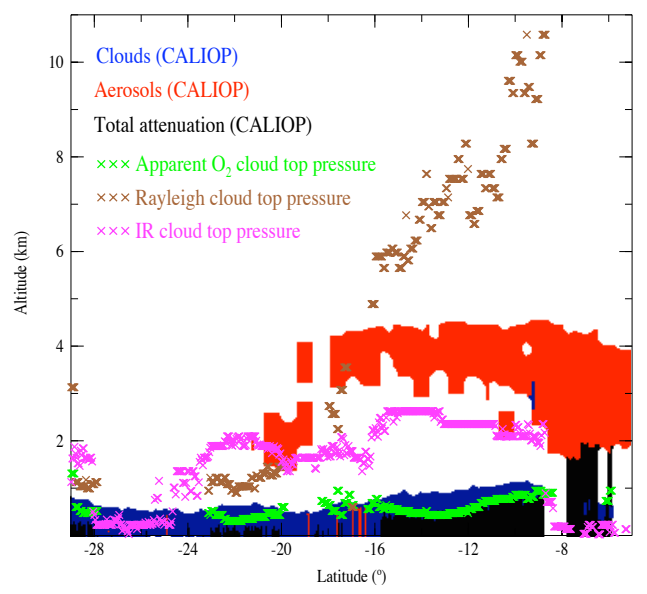

(c)

Fig. 6. A case study on biomass-burning aerosols related to 4 August 2008 acquired over the tropical southeast part of the Atlantic Ocean. (a) RGB composites of POLDER/PARASOL measurements in total radiance and lidar CALIOP track (black line). The POLDER image was produced using a combination of the POLDER spectral bands centered on $0.490 \mu \mathrm{m}, 0.565$ and $0.670 \mu \mathrm{m}$. (b) Total aerosol optical thickness retrieved by POLDER at $0.865 \mu \mathrm{m}$ using the operational algorithm developed for cloud-free ocean scenes. (c) Vertical distribution of the cloud and aerosol layer structures derived from the CALIOP measurements (VFM products) and different estimations of the cloud top height retrieved using passive remote sensing techniques (crosses), as a function of latitude.

ranging from confident liquid phase only to confident ice only $(0<$ phase_index $<200)$. The references for each cloud product previously listed are given in Table 2. For our retrievals, we only consider cloud phase index values ranging between 0 and 80 (only liquid clouds) and between 80 and 120 ("mixed-phase clouds") since AAC scenes are sometimes improperly classified as mixed-phase clouds. We added another criterion to reject multi-layer scenes with cirrus above liquid clouds. This latter criterion is based on the cloud top pressure anomalies observed for scenes with cirrus above liquid clouds $\left(z_{c_{-}} \mathrm{O}_{2}<z_{\mathrm{c} \_}\right.$Rayleigh $\ll z_{\mathrm{c}}$ IR, see Fig. 2 in Waquet et al., 2009a). This latter criterion is only applied when the anomaly is strong $\left(z_{\mathfrak{c}} \mathrm{IR}-z_{\mathrm{c}-} \mathrm{O}_{2}>2 \mathrm{~km}\right.$ and $z_{\mathrm{c}} \mathrm{IR}-z_{\mathrm{c}} \_$Rayleigh $>2 \mathrm{~km}$ ).
Finally, the CALIOP lidar data are used when available to characterize the vertical profile of the atmosphere along the A-train orbit track. We use the aerosol/cloud classification that corresponds to the Lidar Level 2 Vertical Feature Mask (VFM) Product (Vaughan et al., 2004).

\section{Results}

\subsection{Case studies of aerosol transport events}

\subsubsection{Biomass-burning aerosols}

Figure $6 \mathrm{a}$ is a true color composite image illustrating POLDER total radiance observations, acquired over the tropical southeast part of the Atlantic Ocean on 4 August 2008. 


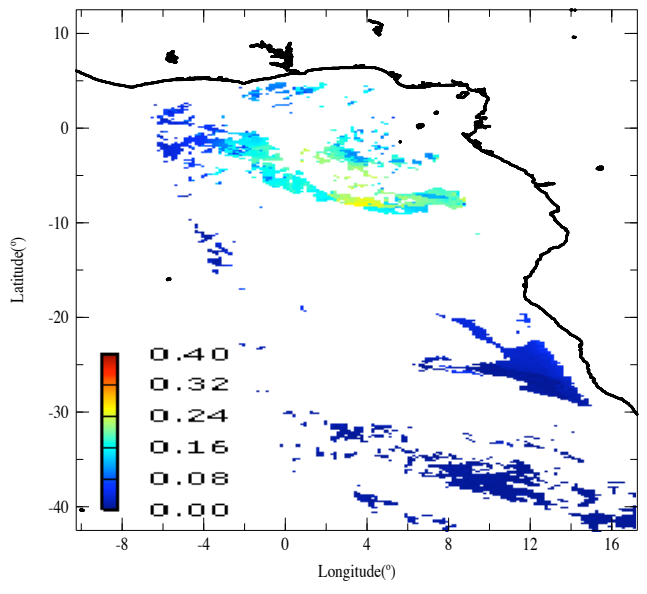

(a)

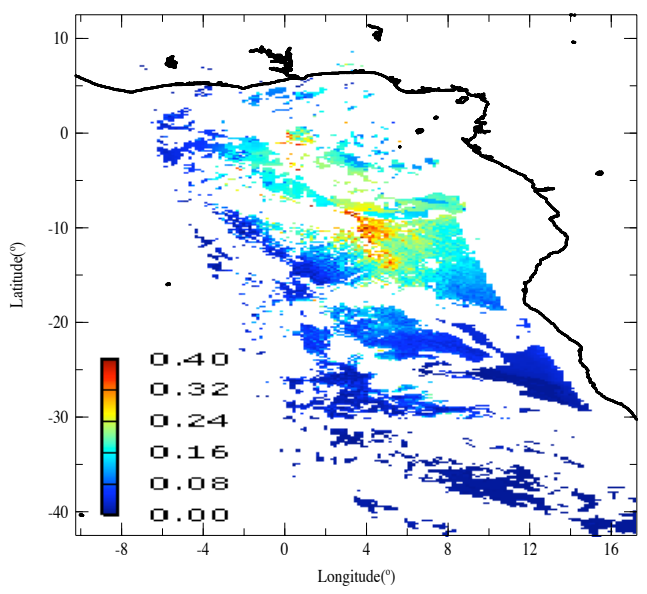

(b)

Fig. 7. Fine-mode scattering optical thickness retrieved by POLDER at $0.865 \mu \mathrm{m}$ over (a) cloud-free ocean scenes and (b) over both cloudfree and cloudy scenes. The cloudy structures are visible in Fig. 6. The corresponding total aerosol optical thickness retrieved only for cloud-free scenes is shown in Fig. 6b.

The CALIOP lidar orbit track is the black line. The transport of biomass-burning aerosols over clouds is expected in this region for this time period (e.g. Waquet et al., 2009a). The region is partially covered by clouds. The total AOT retrieved over cloud-free pixels is reported in Fig. 6b. The largest AOTs $(\approx 0.6)$ are observed over the cloud-free parts of the Gulf of Guinea. The Ångström exponent is about 1 in this region, which indicates that the algorithm retrieves a bimodal size distribution. We know that the algorithm is sensitive to two types of particles, the maritime aerosols (coarsemode particles) located in the boundary maritime layer and the biomass-burning aerosols (mainly fine-mode particles) located in the elevated layer.

We reported the CALIOP mask results in Fig. 6c. An aerosol layer is observed at altitude between 2 and $4 \mathrm{~km}$ above low-level clouds for latitudes ranging between -8.5 and $-21^{\circ}$. For northern latitudes, the lidar signal is too attenuated and the particles located in the lower atmosphere cannot be observed. The cloud top heights retrieved from passive observations (IR, $\mathrm{O}_{2}$ and Rayleigh) are reported in Fig. 6c. The selected POLDER and MODIS pixels centers are the closest to the CALIOP pixels. The anomalies observed between the three different estimates of the cloud top heights for latitudes between -20 and $8.5^{\circ}$ are typical of AAC scenes with biomass-burning aerosols (Waquet et al., 2009a). The IR and Rayleigh methods both largely overestimate the cloud top height with the largest biases observed on $z_{c}$-Rayleigh. The apparent $\mathrm{O}_{2}$ cloud pressure does not appear to be much perturbed by the aerosol layer and tends to slightly underestimate the true cloud top altitude. This last method provides an estimate of the cloud top height that is in-between the geometric middle of the cloud layer and the cloud top height, as expected for low-level single cloud layers (Ferlay et al., 2010). Most of the clouds observed in the POLDER image shown in Fig. 6a correspond to low-level optically thick clouds $\left(0.45 \mathrm{~km}<z_{\mathrm{c}-} \mathrm{O}_{2}<1.05 \mathrm{~km}\right.$, $3.0<$ COT $<18.0$ ) with a cloud thermodynamical phase index of about 10 , which means high probability for liquid phase.

In Fig. 7b, we compare the AOT retrieved above clouds with the fine-mode AOT retrieved by POLDER over cloudfree pixels. Assuming that most of the fine-mode particles are located in the elevated biomass-burning aerosol layer, we expect that both AOTs should be comparable. Figure $7 \mathrm{~b}$ shows a generally good qualitative spatial agreement between the AOTs retrieved with the two methods. The largest AAC optical thicknesses $(>0.3)$ are retrieved over the Gulf of Guinea and are associated with small particles $(\alpha$ of $\approx 2.25$ ). In this region, the AAC optical thicknesses are higher than the AOTs retrieved for ocean scene, but the spatial variability of the fine-mode AOT retrieved over ocean pixels is sometimes questionable. For instance, the fine-mode AOT abruptly changes from about 0.16 to 0.24 (from blue to yellow in the AOT map shown in Fig. 7a) around the point of coordinates longitude $4^{\circ}$ and latitude $-9^{\circ}$. This change is associated with a change in the coarse-mode microphysical properties (the fraction of non-spherical particles has changed). Biomass-burning aerosols are very likely to be strongly absorbing particles. So, we think that the assumption of nonabsorbing particles made in the ocean algorithm might lead to slightly overestimating the coarse-mode AOT and then to consequently underestimating the fine-mode AOT. This hypothesis is supported by the results of the sensitivity analysis presented in Sect. 5.1 showing that the assumption of weak absorption generally leads to the retrieval of a larger coarsemode AOT. 


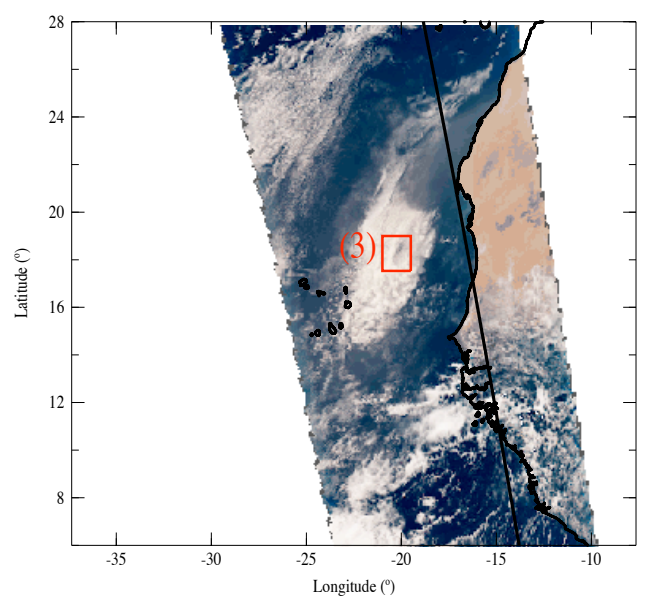

(a)

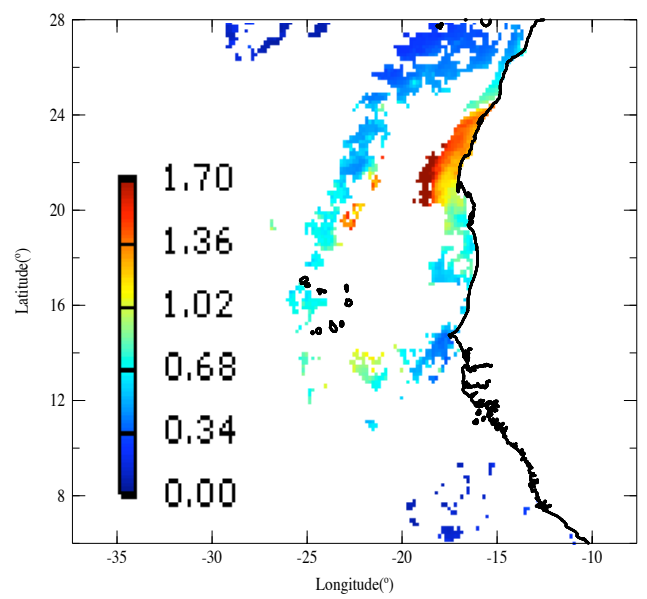

(b)

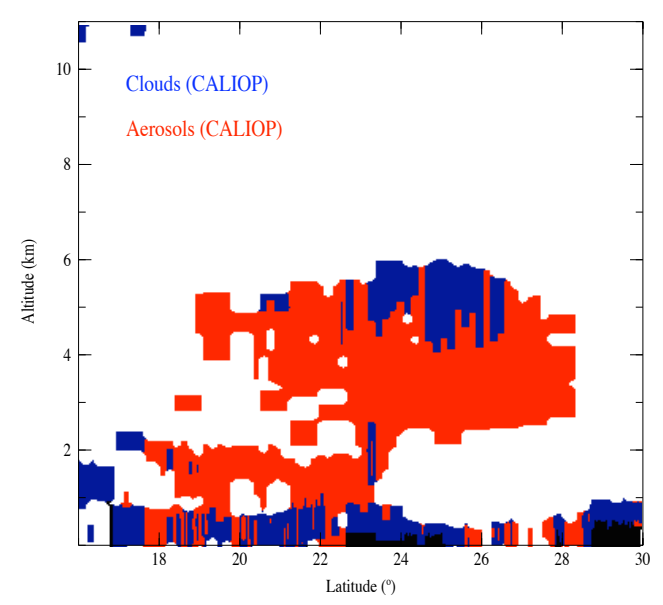

(c)

Fig. 8. Case study on mineral dust particles related to 25 July 2008 acquired over the tropical northeast part of the Atlantic Ocean. Same types of figures as the ones shown in Fig. 6. The cloud top heights retrieved with passive methods are not reported here since the cloud observed by POLDER is outside the CALIOP track.

\subsubsection{Mineral dust aerosols}

We now reported POLDER images acquired over the northeastern tropical Atlantic Ocean on 25 July 2008 and on 4 August 2008, respectively in Figs. 8a and 9a, together with the lidar CALIOP traces. The presence of mineral dust particles above low-level clouds is expected in this region at that time (De Graaf et al., 2007). The transport of mineral dust particles can be observed in cloud-free scenes in Figs. 8a and 9a. An optically thick liquid low-level cloud can be observed $\left(\mathrm{COT}>5\right.$. and $\left.z_{-} \mathrm{O}_{2}<0.4 \mathrm{~km}\right)$ in the case of 25 July. The cloud cover is more fractional and optically thinner than in the case of 4 August. The AOTs retrieved by POLDER over cloud-free ocean scenes are reported in Figs. $8 \mathrm{~b}$ and 9b. Large AOT values can be observed, as large as 1.7, on 25 July 2008. The Ångström exponent is close to zero for both days, indicating a size distribution dominated by the coarse-mode particles. Because of geometrical conditions, the fraction of non-sphericity is only available on 25 July 2008. It indicates that the coarse mode mainly consists of non-spherical particles, which is perfectly consistent with the origins of the aerosol layer.

The presence of mineral dust particles above clouds cannot be insured with the lidar data for the July case, since the optically thick cloud observed by POLDER is outside the CALIOP track (see Fig. 8a). For this thick cloud, the anomalies observed between the three different estimates (not shown) of the cloud top heights remain qualitatively similar to the biomass-burning aerosol case $\left(z_{\mathrm{c}-} \mathrm{O}_{2}<z_{\mathrm{c}-} \mathrm{IR}<z_{\mathrm{c}-}\right.$ Rayleigh) with, however, smaller biases noted on $z_{\mathfrak{c}}$ Rayleigh, resulting from the lower polarization produced by non-spherical particles. For instance, the average values for $z_{\mathrm{c}_{-}} \mathrm{O}_{2}, z_{\mathrm{c}}$ IR and $z_{\mathrm{c}}$ Rayleigh computed for box 3 in Fig. $8 \mathrm{a}$ are equal to $0.275,2.75$ and $3.45 \mathrm{~km}$, 


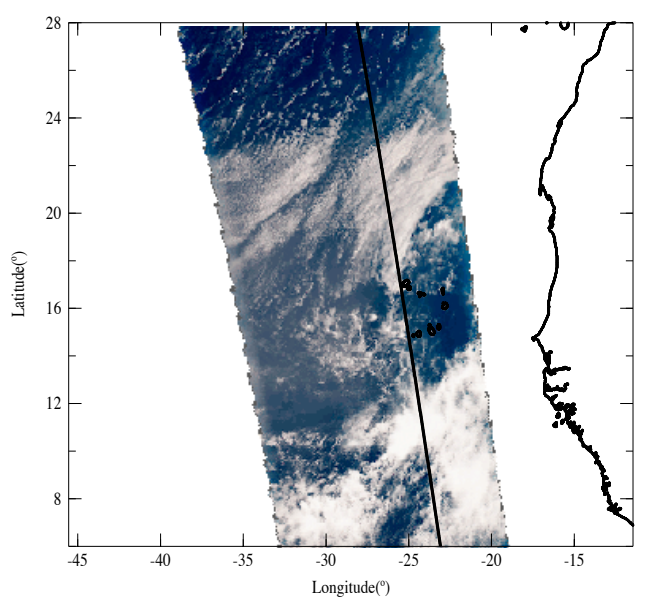

(a)

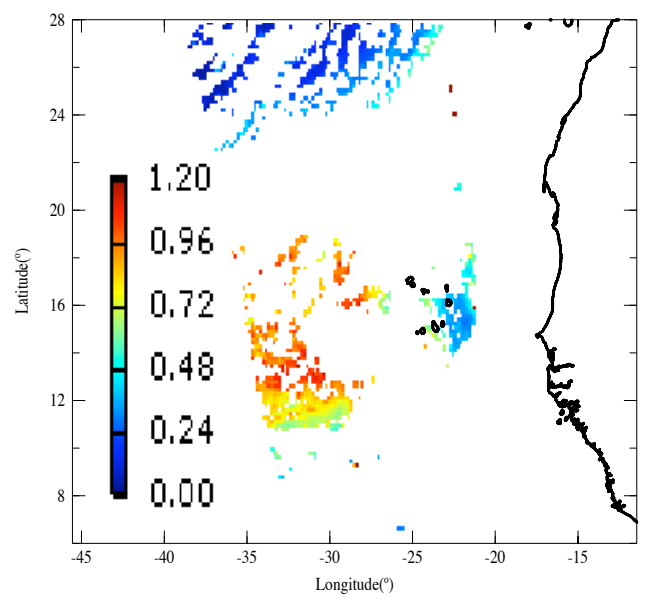

(b)

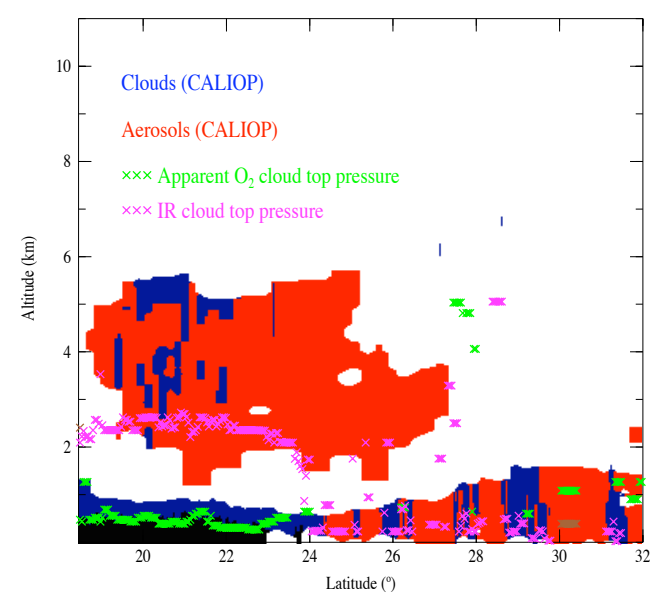

(c)

Fig. 9. Case study on mineral dust particles related to 4 August 2008 acquired over the tropical northeast part of the Atlantic Ocean. Same figures as in Figs. 6 and 7. The so-called "Rayleigh cloud top pressure" is not available for this case due to unfavorable geometric conditions.

respectively. The CALIOP mask results are shown in Fig. 8c. The CALIOP mask shows a complex situation with aerosols detected at different altitudes between the sea surface and $6 \mathrm{~km}$ that are potentially embedded with some optically thin cloudy structures. We observe some abrupt changes in the CALIOP results that we assume to be artificial for the most part since the CALIOP mask is sometimes subject to misclassification between aerosol and cloud layers, especially when dense dust layers are encountered (Chen et al., 2010).

The CALIOP results obtained for the case study on mineral dust particles acquired on 4 August 2008 are reported in Fig. 9c, together with the cloud top height estimates retrieved from POLDER and MODIS. The dust plume is observed at altitudes between 2 and $6 \mathrm{~km}$ above low-level clouds for latitudes ranging between 18 and $24^{\circ}$. The same layer is observed above a maritime boundary layer for latitudes ranging between 24 and $27.5^{\circ}$. The results obtained with the Rayleigh method are not available due to unfavorable geometric conditions (i.e. this method requires observations acquired at small scattering angles that are not available here). The results for $z_{\mathrm{c}_{-}} \mathrm{O}_{2}$ and $z_{\mathrm{c}-\mathrm{IR}}$ remain qualitatively similar to the ones obtained for the two previous cases.

The spatial variability of the AOT of the mineral dust plume transported above clouds on 25 July 2008 is shown in Fig. 10a, together with the AOT retrieved over cloud-free ocean. The map shows that the dust plume is blowing east over the ocean and then southeast above low-level clouds. The AAC algorithm retrieves the dust model included in the LUT with a retrieved Ångström exponent of about 0.4. Figure 10a shows a good qualitative spatial agreement between the AOTs retrieved over cloudy and cloud-free pixels. We, however. note that the AAC optical thicknesses are systematically smaller than the AOD retrieved over cloud-free ocean pixels: respectively, 1.5 and 1.7. Such a difference is not surprising since the AAC optical thickness cannot include the aerosols observed in the lower atmosphere layer as noted by 


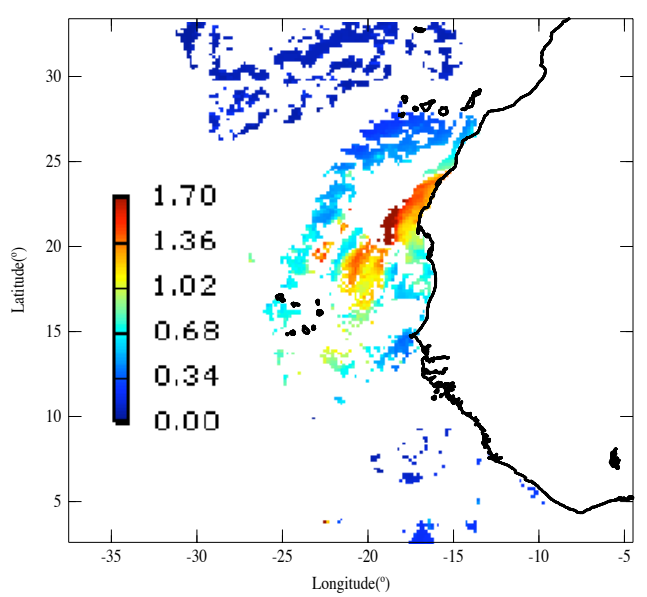

(a)

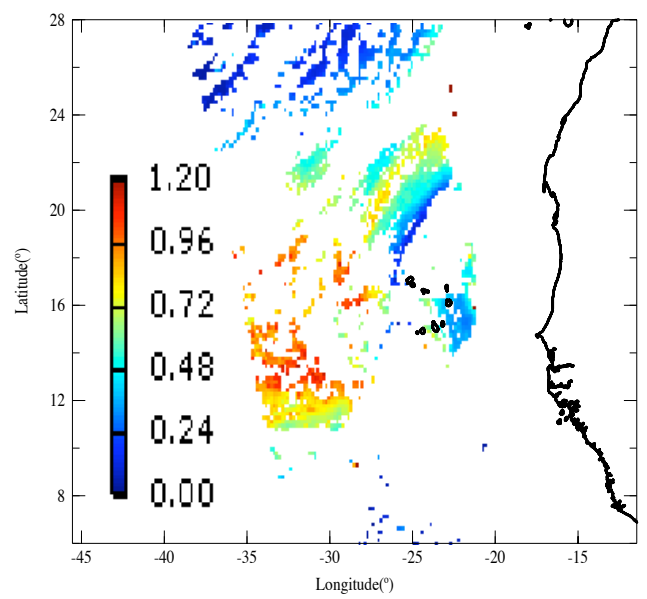

(b)

Fig. 10. Total optical thickness retrieved by POLDER at $0.865 \mu \mathrm{m}$ over both cloud-free ocean scenes and cloudy scenes, for the case studies on mineral dust particles acquired on (a) 25 July 2008 and on (b) 4 August 2008. The cloudy structures are visible in Figs. 8a and 9a for 25 July 2008 and for 4 August 2008, respectively. The corresponding total aerosol optical thickness retrieved only for cloud-free scenes is shown in Figs. 8b and 9b, for 25 July 2008 and for 4 August 2008, respectively.

CALIOP. The results obtained for the mineral dust particles observed on 4 August 2008 are reported in Fig. 10b. The same observations can be made for this second case study. The fact that the algorithm does not retrieve AOT over clouds that are larger than the total column AOT is also a positive sign of the retrieval consistency.

\section{Discussion}

In this section, we further analyze the potential of the POLDER polarization measurements for the retrieval of the aerosol and cloud microphysical properties for the AAC scenes previously described. We use the research algorithm described in Sect. 2.2.1 and all the available angular and spectral polarized measurements provided by the POLDER instrument. We present a sensitivity study analysis that allows one (1) to examine the sensitivity of the POLDER polarization measurements to the different aerosol and cloud microphysical parameters, (2) to evaluate the impacts of these parameters on the retrieved AOT and (3) to study the impacts of the 3-D radiative transfer effects on the retrieved particle microphysics. Then, we explain how we parameterized the mineral dust particle model implemented in the operational algorithm and describe more accurately the microphysical properties of the aerosol and cloud particles observed for the AAC scenes previously described.

\subsection{Sensitivity study analysis}

\subsubsection{Sensitivity study from POLDER measurements}

The research algorithm is flexible and the number of retrieved parameters can be increased or decreased as needed. We did several tests with varying numbers of retrieved parameters in order to provide a sensitivity study. We first investigated the AAC scene with biomass-burning aerosols, referred to as box (1) in Fig. 6a. The solutions obtained for the hyper-pixel defined for this area and for various retrieval schemes are reported in Table 3 . The quantity $\varepsilon$ is the mean squared difference error term calculated between measured and simulated polarized radiances (see Appendix, Eq. A3). This quantity gives a simple measure of the difference between measurements and simulations, assuming a diagonal identity matrix for $\mathbf{C}_{x}$ (no weight) and no a priori knowledge. Note that the quantity $\varepsilon$ is consistent with the definition of the error term considered in the less sophisticated retrieval method described in Sect. 2.2.4. Solution 1 includes the retrieval of the parameters of load and size for the fine particles and the microphysical parameters for the cloud particles. Biomass-burning aerosols are considered as spherical particles, which is a reasonable assumption for this type of aerosols. The value for the spherical fraction (SF) of particles indicated in Table $1(0.5 \pm 0.5)$ is therefore modified and held constant to 1 . Solution 2 is the same as solution 1 but includes the retrieval of the properties of the coarse mode (load and size parameters). Solutions 1 and 2 both assume a weak absorption. Solution 3 is similar to solution 2 with in addition the retrieval of the imaginary part of the complex refractive index (i.e. absorption). Solution 4 is similar to solution 3 but includes the retrieval of the real part of the refractive index. 
Table 3. Retrieved aerosol and cloud parameters for various inversion schemes in the case of a biomass-burning particle layer located above liquid cloud and associated uncertainties ( ). The cloudy area is shown in Fig. 6a (box 1). The different solutions correspond to the adjustment of a different number of parameters. The parameters that are not adjusted during the retrieval process are indicated in bold. $\varepsilon$ is the mean squared error term calculated between the measured and simulated polarized radiances $\left(\times 10^{3}\right)$.

\begin{tabular}{|c|c|c|c|c|c|c|c|c|c|}
\hline $\begin{array}{l}\tau(\lambda) \\
865 \mathrm{~nm} \\
670 \mathrm{~nm} \\
490 \mathrm{~nm}\end{array}$ & $\alpha$ & $\begin{array}{l}r_{\mathrm{eff}, \mathrm{f}} \\
(\mu \mathrm{m})\end{array}$ & $\begin{array}{l}r_{\text {eff,c }} \\
(\mu \mathrm{m})\end{array}$ & $m_{i}$ & $\begin{array}{l}\operatorname{SSA}(\lambda) \\
865 \mathrm{~nm} \\
670 \mathrm{~nm} \\
490 \mathrm{~nm}\end{array}$ & $m_{\mathrm{r}}$ & $\begin{array}{l}\text { Shape } \\
\text { (SF) }\end{array}$ & $\begin{array}{l}r_{\text {eff,cld }}(\mu \mathrm{m}) \\
v_{\text {eff,cld }} \\
m_{\mathrm{r}, \mathrm{cld}}(\lambda) \\
865 \mathrm{~nm} \\
670 \mathrm{~nm} \\
490 \mathrm{~nm}\end{array}$ & $\begin{array}{c}\varepsilon \\
\times 10^{3}\end{array}$ \\
\hline \multicolumn{10}{|c|}{ Solution 1} \\
\hline $\begin{array}{l}0.25(0.01) \\
0.46(0.01) \\
0.82(0.015)\end{array}$ & $\begin{array}{c}2.32 \\
(0.20)\end{array}$ & $\begin{array}{c}0.175 \\
(0.001)\end{array}$ & $\begin{array}{c}\text { No } \\
\text { coarse } \\
\text { mode } \\
\text { particles }\end{array}$ & 0.001 & $\begin{array}{l}0.992\left(10^{-4}\right) \\
0.9935\left(10^{-4}\right) \\
0.9945\left(10^{-4}\right)\end{array}$ & 1.47 & 1 & $\begin{array}{l}8.3(0.3) \\
0.10(0.01) \\
1.330(0.001) \\
1.333(0.003) \\
1.344(0.003)\end{array}$ & 1.229 \\
\hline \multicolumn{10}{|c|}{ Solution 2} \\
\hline $\begin{array}{l}0.29(0.015) \\
0.48(0.02) \\
0.84(0.02)\end{array}$ & $\begin{array}{c}2.0 \\
(0.35)\end{array}$ & $\begin{array}{c}0.171 \\
(0.0015)\end{array}$ & $\begin{array}{c}1.74 \\
(0.12)\end{array}$ & 0.001 & $\begin{array}{l}0.988\left(10^{-4}\right) \\
0.9902\left(10^{-4}\right) \\
0.992\left(10^{-4}\right)\end{array}$ & 1.47 & 1 & $\begin{array}{l}8.3(0.3) \\
0.09(0.015) \\
1.330(0.002) \\
1.334(0.003) \\
1.345(0.003)\end{array}$ & 1.137 \\
\hline \multicolumn{10}{|c|}{ Solution 3} \\
\hline $\begin{array}{l}0.31(0.02) \\
0.51(0.02) \\
0.87(0.025)\end{array}$ & $\begin{array}{c}1.90 \\
(0.36)\end{array}$ & $\begin{array}{c}0.165 \\
(0.002)\end{array}$ & $\begin{array}{c}2.77 \\
(0.43)\end{array}$ & $\begin{array}{c}0.014 \\
(.0035)\end{array}$ & $\begin{array}{l}0.84(0.035) \\
0.875(0.03) \\
0.90(0.025)\end{array}$ & 1.47 & 1 & $\begin{array}{l}8.4(0.3) \\
0.08(0.015) \\
1.331(0.002) \\
1.334(0.003) \\
1.344(0.003)\end{array}$ & 1.051 \\
\hline \multicolumn{10}{|c|}{ Solution 4} \\
\hline $\begin{array}{l}0.30(0.025) \\
0.50(0.02) \\
0.88(0.025)\end{array}$ & $\begin{array}{c}1.96 \\
(0.42)\end{array}$ & $\begin{array}{c}0.171 \\
(0.005)\end{array}$ & $\begin{array}{l}1.85 \\
(1.2)\end{array}$ & $\begin{array}{c}0.017 \\
(0.007)\end{array}$ & $\begin{array}{l}0.835(0.055) \\
0.865(0.045) \\
0.895(0.035)\end{array}$ & $\begin{array}{c}1.45 \\
(0.015)\end{array}$ & 1 & $\begin{array}{l}8.3(0.3) \\
0.08(0.01) \\
1.330(0.002) \\
1.333(0.003) \\
1.343(0.003)\end{array}$ & 0.997 \\
\hline
\end{tabular}

All the solutions allow the POLDER data (not shown) to be robustly modeled and confirm that the polarized measurements are primarily sensitive to the fine-mode scattering AOT and its spectral dependence as well as the cloud microphysical properties. The measurements are also potentially sensitive to the aerosol SSA since the polarization observed at side scattering angles is related to the scattering AOT whereas the effect of attenuation of the aerosol layer on the polarized light reflected by the cloud depends on the total (extinction) AOT. The algorithm shows indeed some sensitivity to the aerosol SSA. We observed that the effect of the absorption on the polarized radiances is rather small but not negligible. Solution 4 includes the most degrees of freedom in terms of retrieved aerosol microphysical parameters, and it retrieves an aerosol model for which the size distribution is dominated by fine-mode particles ( $\alpha$ of about 2) associated with rather strong absorption properties $\left(m_{i}\right.$ of $\left.0.017 \pm 0.007\right)$. The standard deviation for each parameter is small except for the coarse-mode particle effective radius, which tends to indicate that the algorithm is sensitive to most of the parameters considered in solution 4 . The least square error term $\varepsilon$ is minimized for this solution, but other solutions $(1,2,3)$ show rather similar low $\varepsilon$ values. The retrieved AOTs at $0.865 \mu \mathrm{m}$ are rather similar for all solutions, but differences appear for the aerosol microphysical parameters. For instance, the contribution of the coarse-mode particles to the total AOT is larger for solution 2 than for solution 4 , whereas the absorption is much smaller for solution 2 than for solution 4 (not shown). 
Table 4. Description of the particle microphysics used to create synthetic data for AAC scenes with biomass-burning aerosols and synthetic retrievals obtained for different retrieval options. The parameters that are not adjusted during the retrieval process are indicated in bold. $\varepsilon$ is the mean squared error term calculated between the measured and simulated polarized radiances $\left(\times 10^{3}\right)$.

\begin{tabular}{|c|c|c|c|c|c|c|c|c|c|}
\hline $\begin{array}{l}\tau(\lambda) \\
865 \mathrm{~nm} \\
670 \mathrm{~nm} \\
490 \mathrm{~nm}\end{array}$ & $\alpha$ & $\begin{array}{l}r_{\text {eff,f }} \\
(\mu \mathrm{m})\end{array}$ & $\begin{array}{l}r_{\text {eff,c }} \\
(\mu \mathrm{m})\end{array}$ & $m_{i}$ & $\begin{array}{l}\operatorname{SSA}(\lambda) \\
865 \mathrm{~nm} \\
670 \mathrm{~nm} \\
490 \mathrm{~nm}\end{array}$ & $m_{\mathrm{r}}$ & $\begin{array}{c}\text { Shape } \\
\text { (SF) }\end{array}$ & $\begin{array}{l}r_{\text {eff,cld }}(\mu \mathrm{m}) \\
v_{\text {eff,cld }} \\
m_{\mathrm{r}, \mathrm{cld}}(\lambda) \\
865 \mathrm{~nm} \\
670 \mathrm{~nm} \\
490 \mathrm{~nm}\end{array}$ & $\begin{array}{c}\varepsilon \\
\times 10^{3}\end{array}$ \\
\hline
\end{tabular}

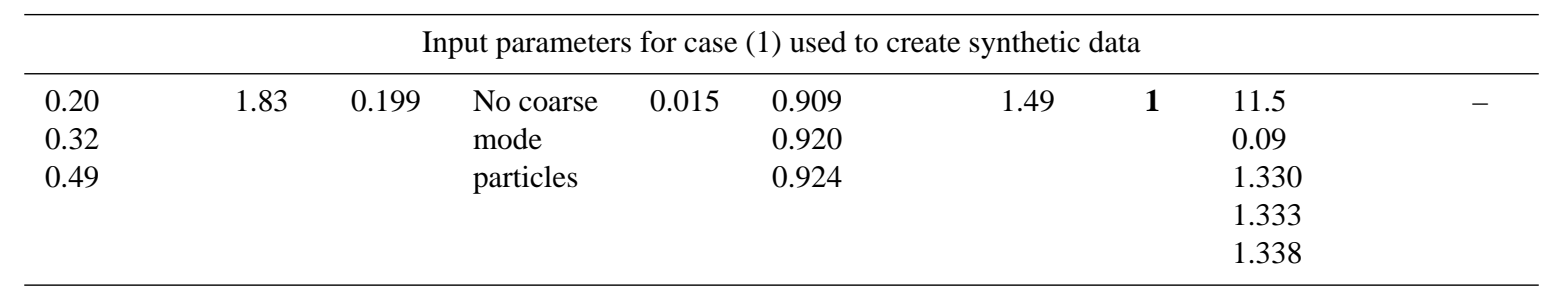

\begin{tabular}{|c|c|c|c|c|c|c|c|c|c|}
\hline \multicolumn{10}{|c|}{ Retrieved parameters for case (1) } \\
\hline $\begin{array}{l}0.21(0.01) \\
0.33(0.01) \\
0.51(0.01)\end{array}$ & $\begin{array}{c}1.74 \\
(0.26)\end{array}$ & $\begin{array}{c}0.190 \\
(0.003)\end{array}$ & $\begin{array}{l}\text { No coarse } \\
\text { mode } \\
\text { particles }\end{array}$ & $\begin{array}{c}0.013 \\
(0.004)\end{array}$ & $\begin{array}{l}0.918(0.023) \\
0.927(0.020) \\
0.930(0.019)\end{array}$ & $\begin{array}{c}1.470 \\
(0.001)\end{array}$ & 1 & $\begin{array}{l}11.49(0.36) \\
0.09(0.010) \\
1.330(0.001) \\
1.333(0.002) \\
1.338(0.002)\end{array}$ & 0.451 \\
\hline
\end{tabular}

\begin{tabular}{|c|c|c|c|c|c|c|c|c|c|}
\hline \multicolumn{10}{|c|}{ Input parameters for case (2) used to create synthetic data } \\
\hline 0.25 & 1.66 & 0.199 & 2.553 & 0.015 & 0.874 & 1.49 & 1 & 11.5 & - \\
\hline 0.37 & & & & & 0.891 & & & 0.09 & \\
\hline \multirow[t]{3}{*}{0.54} & & & & & 0.901 & & & 1.330 & \\
\hline & & & & & & & & 1.333 & \\
\hline & & & & & & & & 1.338 & \\
\hline
\end{tabular}

\begin{tabular}{|c|c|c|c|c|c|c|c|c|c|}
\hline \multicolumn{10}{|c|}{ Retrieved parameters for case (2) } \\
\hline $0.27(0.01)$ & 1.38 & 0.187 & 2.46 & 0.006 & $0.926(0.045)$ & 1.474 & 1 & $11.46(0.39)$ & 0.447 \\
\hline $0.38(0.02)$ & $(0.36)$ & $(0.009)$ & $(0.709)$ & $(0.004)$ & $0.934(0.039)$ & $(0.013)$ & & $0.09(0.011)$ & \\
\hline \multirow[t]{3}{*}{$0.56(0.02)$} & & & & & $0.940(0.034)$ & & & $1.338(0.002)$ & \\
\hline & & & & & & & & $1.331(0.002)$ & \\
\hline & & & & & & & & $1.329(0.001)$ & \\
\hline
\end{tabular}

Retrieved parameters for case (2) when the synthetic data also accounts for the 3-D radiative transfer effects

\begin{tabular}{lcclcccccc}
\hline $0.31(0.01)$ & 1.31 & 0.194 & 2.17 & 0.007 & $0.924(0.042)$ & 1.458 & $\mathbf{1}$ & $11.38(0.41)$ & 0.492 \\
$0.43(0.02)$ & $(0.32)$ & $(0.010)$ & $(0.530)$ & $(0.004)$ & $0.931(0.037)$ & $(0.012)$ & & $0.08(0.011)$ & \\
$0.61(0.02)$ & & & & & $0.936(0.034)$ & & $1.338(0.002)$ & $1.331(0.002)$ \\
& & & & & & & $1.330(0.001)$ & \\
\hline
\end{tabular}

These results suggest that the polarization measurements provided by POLDER do not contain enough information to accurately retrieve the coarse-mode optical thickness and the aerosol absorption properties together.

\subsubsection{Sensitivity study from synthetic data}

To confirm the conclusion obtained in the previous section, we performed a sensitivity study analysis with synthetic data. The particle models and the optical parameters used for the simulations as well as the parameters retrieved with the research algorithm for two different retrieval options are reported in Table 4. We use the viewing geometries associated with the hyper-pixel data shown in Fig. 1a. We added some noise and calibration errors to the simulations to perform a realistic sensitivity study. We considered 3 cases. For case (1), we ignored the presence of coarse-mode particles within the particle size distribution. We considered an AOT of 0.2 at $0.865 \mu \mathrm{m}$. For case (2), we added coarse-mode particles in the simulations (coarse-mode AOT of 0.05 and fine-mode AOT of 0.2 at $0.865 \mu \mathrm{m}$ ). Case (3) is similar to 
case (2), but we reduced the cloud bow magnitude in the simulations respectively by 4,7 and $7 \%$, at $0.490,0.670$ and $0.865 \mu \mathrm{m}$, in order to simulate the 3 -D cloud effects. These values were estimated using the 3 -D radiative transfer code described in Sect. 2.2.3b.

When we only consider fine-mode particles both in the simulations and in the retrieval method (case 1), the algorithm retrieves aerosol absorption properties $\left(m_{i}\right.$ of $0.013 \pm 0.004)$ that agree well with the ones considered in the simulations $\left(m_{i}=0.015\right)$. The retrieved aerosol SSA is also in good agreement with the one used in the simulations. When we include coarse-mode particles both in the simulations and in the retrieval method (case 2), the retrieved absorption properties are underestimated $\left(m_{i}\right.$ of $0.006 \pm 0.004$ instead of 0.015$)$ and the SSA is overestimated $(0.926 \pm 0.045$ instead of 0.874 at $0.865 \mu \mathrm{m})$. These results indicate that the presence of the coarse-mode particles within the particle size distribution perturbs the retrieval of the aerosol absorption properties performed from polarization measurements. These results confirm that the POLDER polarization measurements do not contain enough information to accurately estimate the entire coarse particle properties. This leads to errors in the retrieval of the aerosol absorption properties and then in the retrieved aerosol SSA as the retrieval of the particle size distribution and complex refractive index are connected. The errors in the coarse-mode particle properties also affect the retrieval of the complex refractive index. Finally, the 3-D cloud effects also impact the retrieval of the aerosol properties. It mainly impacts the retrieval of the AOT (an overestimation of $20 \%$ or 0.05 at $0.865 \mu \mathrm{m}$ ) and also slightly affects the retrieval of the aerosol microphysics (e.g. the real refractive index is underestimated).

We note also that the fine-mode particle size, the Ångström exponent and the cloud microphysical properties are accurately retrieved for the three cases. These results confirm that the retrieval strategy used in the operational algorithm is well adapted for the retrieval of the biomass-burning aerosol properties observed above clouds. For the operational algorithm, we recall that we use a constant value for the complex refractive index and that we only try to retrieve the AOT and the Ångström exponent using fine-mode particle models and data acquired for scattering angles smaller than $130^{\circ}$, where the 3-D cloud effects are negligible. The main benefit of using the research algorithm to analyze the POLDER data acquired for biomass-burning AAC scenes is therefore to obtain an accurate estimate of the microphysical properties of the cloud particles located below the aerosol layer.

\subsection{Feasibility study for simultaneous retrieval of aerosol and cloud properties}

\subsubsection{Case of biomass-burning aerosols above clouds}

We describe hereafter the retrieval option that is finally preferred to simultaneously retrieve the aerosol and cloud properties for biomass-burning AAC scenes. Since we cannot accurately retrieve all the aerosol properties, it seems reasonable to consider some assumptions on the aerosol microphysics, for instance on the coarse-mode particle properties and on the real refractive index. For solution 5, we made assumptions for the coarse-mode particle optical thickness $(0.015$ at $0.865 \mu \mathrm{m})$, the coarse-mode particle effective radius $\left(r_{\mathrm{eff}, \mathrm{c}}=1.97 \mu \mathrm{m}\right)$ and for the real refractive index $\left(m_{\mathrm{r}}=1.47\right)$. The aerosol parameters included in the vector $\boldsymbol{X}$ are therefore $N_{\mathrm{f}}, r_{\mathrm{g}, \mathrm{f}}, \sigma_{\mathrm{f}}$ and $m_{i}$. The cloud parameters included in the vector $\boldsymbol{X}$ are $r_{\text {eff,cld }}, v_{\text {eff,cld }}$ and $m_{\mathrm{r}, \mathrm{cld}}(\lambda)$. The aerosol SSA depends on both particle absorption and size distribution. Thus, any error in the assumptions made for the aerosol properties (e.g. for the size or the coarse-mode AOT) directly affects its retrieval. As it is difficult to assess the validity of our assumptions, we test solution 5 to ensure that it can provide an estimate of the aerosol SSA.

We applied this retrieval option to the hyper-pixel defined for the AAC scene with biomass-burning aerosols, referred to as box (1) in Fig. 6a. The results are reported in Table 5 as case (1). The hyper-pixel data and the simulations are shown in Fig. 1a. Solution 5 provides an estimate of the aerosol SSA equal to $0.815( \pm 0.045)$ at $0.865 \mu \mathrm{m}$. This is consistent with biomass-burning aerosols in South Africa according to AERONET sun-photometer observations (Dubovik et al., 2002), which give a mean aerosol SSA of $0.80 \pm 0.004$ (at $0.87 \mu \mathrm{m})$ and a mean imaginary part of the complex refractive index of $0.021 \pm 0.004$ for biomass-burning aerosols observed in the center of South Africa (Zambia). Our estimate also agrees rather well with the one provided by Leahy et al. (2007), who found an aerosol single scattering albedo of $0.85 \pm 0.02$ (regional mean and uncertainty at $0.55 \mu \mathrm{m}$ ), on the basis of an updated analysis of remote and in situ measurements performed during the Southern African Regional Science Initiative 2000 (SAFARI).

We reported the results obtained for two other hyper-pixels in Table 5: case (2) corresponds to an AAC scene encountered for the case study on biomass-burning aerosols that is referred to as box (2) in Fig. 6a and case (3) corresponds to data acquired on 18 August 2008 for clouds observed in pristine conditions between South Africa and Antarctica (not shown). Solution 5 was used for both cases. The algorithm retrieves a small value of AOT for case (2) but still retrieves a size distribution dominated by small particles, which suggests a continental origin. The retrieved AOT is also very small $(0.022 \pm 0.003)$ for case (3), and the type of particles thus cannot be identified since the Ångström exponent cannot be accurately retrieved anymore $(\alpha=0.88 \pm 1.08)$. Note that some difficulties in the modeling of the polarized radiances can be observed for case (2) for large scattering angles $\left(\approx 180^{\circ}\right)$ that are not clearly understood (see Fig. 1c). We can only speculate that it could be the result of the scene spatial heterogeneity. In a general way, we note that significant errors in the modeling of the polarized radiances appear in the cloud bow region when the AAC optical thickness is 
Table 5. Aerosol and cloud retrieved parameters and associated uncertainties () or min and max values [] retrieved with solution 5 for various situations and with solution $5^{*}$ for the case related to a dust layer located above clouds. The parameters that are not adjusted during the retrieval process are indicated in bold. $\varepsilon$ is the mean squared error term calculated between the measured and simulated polarized radiances $\left(\times 10^{3}\right)$.

\begin{tabular}{|c|c|c|c|c|c|c|c|c|c|}
\hline $\begin{array}{l}\tau \text { at } \\
865 \mathrm{~nm}\end{array}$ & $\alpha$ & $\begin{array}{l}r_{\mathrm{eff}, \mathrm{f}} \\
(\mu \mathrm{m})\end{array}$ & $\begin{array}{l}r_{\text {eff,c }} \\
(\mu \mathrm{m})\end{array}$ & $m_{i}$ & $\begin{array}{l}\mathrm{SSA} \text { at } \\
865 \mathrm{~nm}\end{array}$ & $m_{\mathrm{r}}$ & $\begin{array}{c}\text { Shape } \\
\text { (SF) }\end{array}$ & $\begin{array}{l}r_{\text {eff,cld }} \\
(\mu \mathrm{m}) \\
V_{\text {eff,cld }} \\
m_{\text {r,cld }} \\
\text { at } 865 \mathrm{~nm}\end{array}$ & $\begin{array}{c}\varepsilon \\
\times 10^{3}\end{array}$ \\
\hline
\end{tabular}

\begin{tabular}{|c|c|c|c|c|c|c|c|c|c|}
\hline $\begin{array}{l}0.28 \\
(0.01)\end{array}$ & $\begin{array}{c}2.17 \\
(0.23)\end{array}$ & $\begin{array}{c}0.165 \\
(0.0025)\end{array}$ & 1.97 & $\begin{array}{c}0.024 \\
(0.0065)\end{array}$ & $\begin{array}{c}0.815 \\
(0.045)\end{array}$ & 1.47 & 1 & $\begin{array}{l}8.5(0.30) \\
0.09(0.015) \\
1.331(0.002)\end{array}$ & 1.028 \\
\hline
\end{tabular}

Case 2: case study with biomass-burning aerosols acquired on 4 August 2008, with few aerosols above clouds (see Fig. 6a, box 2). The polarized measurements are shown in Fig. 1c.

\begin{tabular}{lccccccccc}
\hline 0.063 & 1.80 & 0.148 & $\mathbf{1 . 9 7}$ & {$[0 ; 0.0055]$} & {$[1 ; 0.93]$} & $\mathbf{1 . 4 7}$ & $\mathbf{1}$ & $9.21(0.13)$ & 1.584 \\
$(0.004)$ & $(0.48)$ & $(0.006)$ & & & & & & & $0.045(0.005)$ \\
& & & & & & & $1.331(0.001)$ & \\
\hline
\end{tabular}

Case 3: a very clear case with only liquid clouds far away from continental sources of aerosols, acquired on 18 August 2008 (not shown). The polarized measurements are shown in Fig. 1d.

\begin{tabular}{lccccccccc}
\hline 0.022 & 0.88 & 0.19 & $\mathbf{1 . 9 7}$ & {$[0 ; 0.013]$} & 0.9 & $\mathbf{1 . 4 7}$ & $\mathbf{1}$ & $10.67(0.12)$ & 0.958 \\
$(0.003)$ & $(1.08)$ & $(0.023)$ & & & $(0.1)$ & & & $0.0087(0.0015)$ & \\
& & & & & & & & $1.329(0.001)$ & \\
\hline
\end{tabular}

Case 4: case study on mineral dust particles above clouds acquired on 25 July 2008 (see Fig. 8a, box 3).

The polarized measurements are shown in Fig. 1b.

\begin{tabular}{lccccccccc}
\hline 1.05 & 0.35 & 0.30 & $\mathbf{2 . 5 5}$ & 0.0007 & 0.983 & $\mathbf{1 . 4 7}$ & 0.11 & $12.3(1.46)$ & 0.950 \\
$(0.07)$ & $(0.5)$ & $(0.045)$ & & $(0.000035)$ & $(0.002)$ & & $(0.07)$ & $0.11(0.036)$ & \\
& & & & & & & & $1.329(0.003)$ & \\
\hline
\end{tabular}

small (see Fig. 1c and d). These are most probably due to 3-D cloud effects. Nevertheless, these two results indicate that the AAC optical thickness progressively decreases as we move away from South Africa and that solution 5 remains robust even when the AOT becomes small.

\subsubsection{Case of mineral dust particles above clouds}

For mineral dust AAC scenes, we modified solution 5 to include two additional parameters in the retrieval scheme in order to be able to reproduce the POLDER data. Solution $5^{*}$ is thus similar to solution 5 but includes the retrieval of the coarse-mode AOT and the retrieval of the fraction of SF. The aerosol parameters included in the vector $\boldsymbol{X}$ are therefore: $N_{\mathrm{f}}$, $N_{\mathrm{c}}, r_{\mathrm{g}, \mathrm{f}}, \sigma_{\mathrm{f}}, m_{i}$ and SF. We applied solution $5^{*}$ to the AAC scene with mineral dust particles, referred to as box (3) in Fig. 8a, which was observed on 25 July 2008 . The results are reported in Table 5 as case (4).

The algorithm retrieves AOT values larger than 1 and a large amount of non-spherical particles. The algorithm then retrieves a size distribution dominated by non-spherical coarse-mode particles that shows much smaller absorption properties than biomass-burning aerosols. Mineral dust particles also absorb the solar light due to the presence of iron oxide in their mineral composition (Derimian et al., 2008a). However, dust remains less absorbing than biomass-burning aerosols, except probably for cases where it is mixed with carbonaceous material (Derimian et al., 2008b). Note that we should have retrieved the spectral dependence for the imaginary part of the complex refractive index since mineral dust particles typically show slightly higher absorption properties for shorter visible wavelengths $(0.49 \mu \mathrm{m})$ than for larger wavelengths $(0.67$ and $0.865 \mu \mathrm{m})$. We, however, choose to hold constant this parameter with wavelength to limit the number of retrieved parameters. This would have to be revised in case shorter wavelength observations were to be incorporated.

This particle model is the mineral dust particle model implemented in the operational algorithm. It was used to retrieve the AOT above clouds shown in Fig. 10a and b. This is justified since this model allows the POLDER data to be 
Table 6. Comparisons between the droplet effective radii $\left(r_{\text {eff,cld }}\right)$ retrieved with MODIS and POLDER and associated uncertainties for POLDER $( \pm)$. Scenes with aerosols above clouds $(0.06<\tau<1.05)$ and a cloudy scene observed in pristine conditions $(\tau$ of about 0.02$)$.

\begin{tabular}{lllll}
\hline & $\begin{array}{l}\text { Dust } \\
\text { (25 July 2008) }\end{array}$ & $\begin{array}{l}\text { Biomass } \\
\text { (4 August 2008, } \\
\text { see box 1 in Fig. 6a) }\end{array}$ & $\begin{array}{l}\text { Biomass } \\
\text { (4 August 2008, } \\
\text { see box 2 in Fig. 6a) }\end{array}$ & $\begin{array}{l}\text { Clear case } \\
\text { (18 August 2008) }\end{array}$ \\
\hline$\tau$ at $0.865 \mu \mathrm{m}$ & $1.05( \pm 0.07)$ & $0.28( \pm 0.01)$ & $0.063( \pm 0.004)$ & $0.022( \pm 0.003)$ \\
\hline $\begin{array}{l}\text { MODIS } \\
r_{\text {eff,cld }}(\mu \mathrm{m})\end{array}$ & 12.1 & 9 & 10.3 & 12.9 \\
\hline $\begin{array}{l}\text { POLDER } \\
r_{\text {eff,cld }}(\mu \mathrm{m})\end{array}$ & $12.3( \pm 1.5)$ & $8.5( \pm 0.3)$ & $9.21( \pm 0.13)$ & $10.7( \pm 0.12)$ \\
\hline
\end{tabular}

produced well (see Fig. 1b) and also because the retrieved optical and microphysical properties (i.e. Ångström exponent, complex refractive index and shape) are realistic for mineral dust particles according to Dubovik et al. (2002).

\subsubsection{Retrieval of cloud droplet properties}

The parameters retrieved with the research algorithm for the cloud droplets are reported in Table 5. The retrieved real refractive index values are in good agreement with what we expect for cloud droplets made of pure water (Hale and Querry, 1973). Our algorithm retrieves droplet effective radii varying between 8 and $12 \mu \mathrm{m}$ with no peculiar geographical tendency. The retrieved droplet size distribution is much narrower (small values of effective variance) for the clouds observed southeast of South Africa (18 August 2008) than for the clouds observed over the two other oceanic tropical regions located closer to Africa. This is in good agreement with the results of Bréon and Doutriaux-Boucher (2005), who found that the droplet effective variance is generally much smaller for the clouds observed in subtropical and high-latitude oceans than for continental regions and other oceanic regions. The reasons for this tendency cannot be currently established with confidence. We recall that the droplet effective variance was not much studied from space and that this parameter depends on the dynamical evolution of clouds (Politovich, 1993) and on the origin of the air mass (continental or maritime) (Martin et al., 1994).

We also compared the droplet effective radii retrieved with POLDER with those retrieved by MODIS. Table 6 show some comparisons performed for various scenes with aerosols above clouds and for the fields of clouds observed in pristine conditions. The droplet effective radius reported for MODIS is a mean value computed over the $200 \mathrm{~km} \times 200 \mathrm{~km}$ area. Differences are expected between these two estimates since the polarized measurements are sensitive to droplets located at the top of the cloud layer whereas the MODIS total radiance measurements are sensitive to droplets located deeper in the cloud layer (Bréon and Doutriaux-Boucher, 2005). Another sources of differences are (1) biases expected on the MODIS retrieved droplet effective radius for AAC scenes with absorbing aerosols and (2) uniqueness of the droplet effective variance in the MODIS algorithm (0.13). Bréon and Doutriaux-Boucher (2005) found a systematic MODIS high bias of $2 \mu \mathrm{m}$ in oceanic regions for droplet effective radii larger than $7 \mu \mathrm{m}$. This is close to what we observe for the clouds in pristine conditions. The departures that we observed for AAC scenes are smaller probably because the droplet effective radii retrieved by MODIS are underestimated due to the presence of absorbing AAC (Haywood et al., 2004).

\section{Conclusions}

This study confirms that passive sensors with angular, spectral and polarized capabilities have a strong potential for retrieving the optical and microphysical properties of aerosol above clouds (AAC). An interesting result of this study is that polarized measurements acquired in the cloud bow can be used to retrieve the optical thickness of the mineral dust particles residing above liquid clouds. These large non-spherical particles do not much polarize light but strongly attenuate the polarized cloud bow generated by the liquid cloud layer beneath. The spectral attenuation can be used to qualitatively identify the nature of the particles (coarse- or fine-mode particles), whereas the magnitude of the attenuation is related to the optical thickness of the aerosol layer.

We developed two different algorithms to analyze the POLDER data for AAC scenes. The first one, the so-called research algorithm, allows a simultaneous retrieval of the aerosol and cloud properties and uses POLDER data aggregated at a coarse resolution to have a sufficient angular sampling. The method retrieves the mean properties of the observed particles under the assumption of spatial homogeneity. For clouds, this method also allows for accurate retrieval of the cloud droplet effective variance and the cloud droplet effective radius. Our results tend to confirm that the droplet size distribution is narrow in high-latitude ocean regions and that the droplet effective radius retrieved from polarization measurements is generally slightly smaller than the one retrieved by passive sensors that uses total radiance 
measurements, such as the MODIS instrument (departures smaller than $2 \mu \mathrm{m}$ ). In addition, we show that the aerosol parameters that can be retrieved with the research algorithm are the Aerosol Optical Thickness (AOT), the fine-mode particle size and the Ångström exponent. The fraction of spherical particles can be also retrieved for mineral dust AAC scenes. The coarse-mode particle size, the relative contribution of the two modes to the total AOT as well as the complex refractive index cannot be estimated with confidence with this method.

An operational algorithm was developed to retrieve the aerosol properties for AAC scenes at a finer spatial resolution and at a large scale. This method retrieves the AOT and the Angström exponent for the fine-mode particles and the AOT for mineral dust particles using a non-spherical particle model. With respect to the algorithm described in Waquet et al. (2009a), we improved the accuracy of the modeling, included a realistic mode for mineral dust particles and developed a retrieval strategy that takes advantage of the measurements acquired in the cloud bow direction. The method is, however, limited to observations acquired for optically thick clouds (optical thickness $>5$ ) and only considers a finite number of aerosol models. We compared the AOTs retrieved above clouds with ones retrieved closely over clearsky ocean pixels. We found maximal differences of 0.2 in AOT at $0.865 \mu \mathrm{m}$ that can be explained either by the assumptions used for the microphysical properties of the aerosols, which are different in the two algorithms, or because the algorithm developed for cloud-free ocean scenes measures the aerosol load integrated over the entire atmospheric column whereas the AAC algorithm only retrieves the AOT of the particles residing above the cloud top.

From simulated data, we also showed that the magnitude of the cloud bow in polarization cannot be accurately estimated with a plane parallel radiative transfer code. The errors for the modeling of the polarized radiances vary between 4 and $8 \%$ depending on wavelength and viewing geometry. It impacts the retrieval of the AOT by around $6 \%$ when a mineral dust model is used to retrieve the AOT and can reach $20 \%$ if the particle microphysical properties and the AOT are simultaneously retrieved. However, according to our results, the 3-D effects do not much affect the retrieval of the cloud microphysics performed from polarization measurements. But we considered only one type of heterogeneity (spatial variability in the cloud optical thickness) and a limited number of cases and rather homogenous clouds. More research is therefore needed to better quantify the impacts of the 3-D cloud effects on the retrieval of the particle microphysics observed in cloudy scenes.

Any of the two methods described allow the estimation of the aerosol absorption properties and the aerosol single scattering albedo (SSA). However, it is a key parameter for the estimate of the AAC radiative direct forcing. Some assumptions on the aerosol absorption properties will therefore be considered in order to estimate the AAC direct radiative forcing with the data provided by the operational algorithm. For example, a climatology of the aerosol absorption properties derived from ground-based sun-photometer measurements could be used.

In order to better characterize the AAC properties, the AOT retrieved with the lidar CALIOP could be considered in the future to check the coherence of our retrievals made over clouds or to better constrain the retrieval of the aerosol microphysics using innovative synergetic approaches. Other POLDER data could be also potentially included in the method, such as the total radiance measurements, which provide more sensitivity to aerosol absorption properties. We, however, point out that the present algorithm, solely based on the use of polarization measurements, has the high advantage, with respect to other passive methods, of being independent from the cloud layer albedo.

A rather strong positive radiative forcing as well as significant biases on the retrieved cloud properties are expected when a high loading of strong absorbing aerosols is present above clouds. First results obtained with POLDER indicate large mean AOTs above clouds for oceanic regions near the coasts of South Africa for biomass-burning aerosols; even larger mean AOTs above clouds are retrieved near the coasts of Senegal. In order to refine our assement on radiative forcing, more investigations are needed to better describe the spatial and temporal variability of the AAC properties. Our next step is thus the analysis of the complete archive of POLDER data. This would provide a first global estimate of the properties of the aerosols suspended above clouds and thus the opportunity to first estimate the very uncertain aerosol direct forcing over cloudy skies.

\section{Appendix A}

The retrieval error covariance matrix for the optical thickness $\tau$ is

$C_{\tau}=\mathbf{K}_{\tau} \mathbf{C}_{X} \mathbf{K}_{\tau}^{\mathrm{T}}$,

where $\mathbf{K}_{\tau}$ is the Jacobian matrix for $\tau$. The same formula stands for the aerosol single scattering albedo $\left(\omega_{0}\right)$ and effective radius $\left(r_{\text {eff }}\right)$.

The effective radius, $r_{\text {eff }}$, for lognormal size distribution is defined as

$r_{\mathrm{eff}}=r_{\mathrm{g}} \exp \left(\frac{5}{2} \sigma^{2}\right)$.

Mean squared error term $\varepsilon$ calculated between the measured and calculated polarized radiances is as follows:

$\varepsilon=\sqrt{\frac{1}{N_{\Theta} N_{\lambda}} \sum_{i=1}^{N_{\Theta}} \sum_{j=1}^{N_{\lambda}}\left[L_{i j}^{\mathrm{mes}}(\Theta)-L_{i j}^{\mathrm{calc}}(\Theta)\right]^{2}}$, 
where $N_{\Theta}$ and $N_{\lambda}$ are respectively the number of selected viewing directions and the number of channels.

Phase function truncation

The SOS code requires a Legendre polynomial expansion of the phase matrix. The forward peak of the phase function (i.e. the P11 element of the phase matrix) is generally sharp for large particles such as cloud particles, which requires increasing the number of terms in the expansion of the phase matrix. A truncation procedure of the forward scattering peak is implemented in the SOS code (Potter, 1970; Nakajima and Tanaka, 1988). This procedure allows a faster modeling of the radiances. We, however, noted that this procedure introduces small errors in the modeling of the upwelling polarized radiance under specific circumstances that are encountered in this paper. Errors appear when large spherical particles are considered and when the polarized radiance is saturated (optical thickness $>3$ ). Significant errors appear in the primary cloud bow region. The magnitude of the primary cloud bow is overestimated by $7.5 \%$ when the procedure of truncation is invoked. Calculations performed for a truncation applied to scattering angles between 0 and $16^{\circ}$, for a droplet effective radius of $10 \mu \mathrm{m}$, a droplet effective variance of 0.06 , cloud optical thickness of 5 and a sun zenith angle of $37^{\circ}$. The reasons for this issue are not fully understood and the solving of this technical problem will be attempted in a future effort. In the research algorithm, we use an exact 1-D modeling (no truncation) at the end of each step in the iteration to compare the observations to the simulations, whereas the intermediate calculations (i.e. the Jacobian matrix elements) are performed using the approximation of truncation.

Acknowledgements. The authors acknowledge the use of resources provided by the European Grid Infrastructure. For more information, please refer to the EGI-InSPIRE paper (http://go.egi.eu/pdnon). The authors are very grateful to CNES and NASA for providing the POLDER, MODIS and CALIOP data used in this study. We thank the ICARE data and services center for providing access to the data. This work has been supported by CNES and the Université Lille 1.

Edited by: M. King

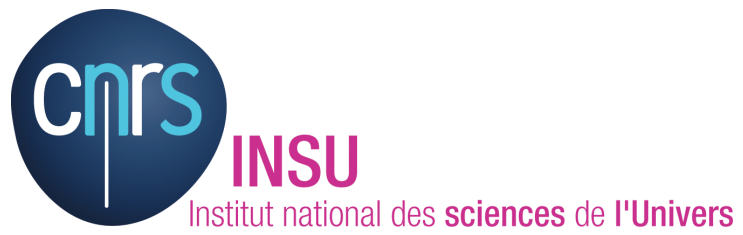

The publication of this article is financed by CNRS-INSU.

\section{References}

Ackerman, A. S., Toon, O. B., Stevens, D. E., Heymsfeld, A. J., Ramanathan, V., and Welton, E. J.: Reduction of Tropical Cloudiness by Soot, Science, 288, 1042-1047, doi:10.1126/science.288.5468.1042, 2000.

Ackermann, J.: The extinction-to-backscatter ratio of tropospheric aerosol: A numerical study, J. Atmos. Ocean. Tech., 15, 10431050, 1998.

Bréon, F.-M and Doutriaux-Boucher, M.: A comparison of cloud droplet radii measured from space, IEEE T. Geosci. Remote, 43, 1796-1805, 2005.

Bréon, F.-M. and Goloub, P.: Cloud Droplet Effective Radius from Spaceborne Polarization Measurements, Geophys. Res. Lett., 25, 1879-1882, 1998.

Bréon, F.-M., Tanré, D., and Generoso, S.: Aerosol effect on cloud droplet size monitored from satellite, Science, 295, 834-838, 2002.

Cattrall, C., Reagan, J., Thome, J. K., and Dubovik, O.: Variability of aerosol and spectral lidar and backscatter and extinction ratios of key aerosol types derived from selected aerosol robotic network locations, J. Geophys. Res., 110, D10S11, doi:10.1029/2004JD005124, 2005.

Chand, D., Wood, R., Anderson, T. L., Satheesh, S. K., and Charlson, R. J.: Satellite-derived direct radiative effect of aerosols dependent on cloud cover, Nat. Geosci., 2, 181-184, 2009.

Chen, B., Huang, J., Minnis, P., Hu, Y., Yi, Y., Liu, Z., Zhang, D., and Wang, X.: Detection of dust aerosol by combining CALIPSO active lidar and passive IIR measurements, Atmos. Chem. Phys., 10, 4241-4251, doi:10.5194/acp-10-4241-2010, 2010.

Coddington, O. M., Pilewskie, P., Redemann, J., Platnick, S., Russell, P. B., Schmidt, K. S., Gore, W. J., Livingston, J., Wind, G., and Vukicevic, T.: Examining the impact of overlying aerosols on the retrieval of cloud optical properties from passive remote sensing, J. Geophys. Res., 115, D10211, doi:10.1029/2009JD012829, 2010.

Cornet, C., Labonnote, L. C., and Szczap, F.: Three-dimensional Polarized Monte-Carlo Atmospheric Radiative Transfer Model (3DMCPOL): 3D Effects on Polarized Visible Reflectances of a Cirrus Cloud, J. Quant. Spectrosc. Ra., 111, 174-186, doi:10.1016/j.jqsrt.2009.06.013, 2010.

De Graaf, M., Stammes, P., and Aben, E. A. A.: Analysis of reflectance spectra of UV-absorbing aerosol scenes measured by SCIAMACHY, J. Geophys. Res., 112, D02206, doi:10.1029/2006JD007249, 2007.

De Graaf, M., Tilstra, L. G., Wang, P., and Stammes, P.: Retrieval of the aerosol direct radiative effect over clouds from spaceborne spectrometry, J. Geophys. Res., 117, D07207, doi:10.1029/2011JD017160, 2012.

Derimian, Y., Karnieli, A., Kaufman, Y. J., Andreae, M. O., Andreae, T. W., Dubovik, O., Maenhaut, W., and Koren, I.: The role of iron and black carbon in aerosol light absorption, Atmos. Chem. Phys., 8, 3623-3637, doi:10.5194/acp-8-3623-2008, 2008a.

Derimian, Y., Léon, J.-F., Dubovik, O., Chiapello, I., Tanré, D., Sinyuk, A., Auriol, F., Podvin, T., Brogniez, G., and Holben, B. N.: Radiative properties of aerosol mixture observed during the dry season 2006 over M'Bour, Senegal (African Monsoon Multidisciplinary Analysis campaign), J. Geophys. Res., 113, D00C09, doi:10.1029/2008JD009904, 2008b. 
Dubovik, O., Holben, B. N., Eck, F. T., Smirnov, A., Kaufman, J. Y., King, D. M., Tanré, D., and Slutsker, I.: Variability of absorption and optical properties of key aerosol types observed in worldwide locations, J. Atmos. Sci., 59, 590-608, 2002.

Dubovik, O., Sinyuk, A., Lapyonok, T., Holben, B. N., Mishchenko, M., Yang, P., Eck, T. F., Volten, H., Muñoz, O., Veihelmann, B., van der Zande, W.J., Leon, J.-F., Sorokin, M., and Slutsker, I.: Application of spheroid models to account for aerosol particle nonsphericity in remote sensing of desert dust, J. Geophys. Res., 111, D11208, doi:10.1029/2005JD006619, 2006.

Ferlay, N., Thieuleux, F., Cornet, C., Davis, A. B., Dubuisson, P., Ducos, F., Parol, F., Riédi, J., and Vanbauce, C.: Toward new inferences about cloud structures from multidirectional measurements in the oxygen A band: Middle-of-cloud pressure and cloud geometrical thickness from POLDER3/PARASOL, J. Appl. Meteorol. Clim., 49, 2492-2507, doi:10.1175/2010JAMC2550.1, 2010.

Forster, P., Ramaswamy, V., Artaxo, P., Berntsen, T., Betts, R., Fahey, D. W., Haywood, J., Lean, J., Lowe, D. C., Myhre, G., Nganga, J., Prinn, R., Raga, G., Schulz, M., and Van Dorland, R.: Changes in Atmospheric Constituents and in Radiative Forcing, in: Climate Change 2007: The Physical Science Basis. Contribution of Working Group I to the Fourth Assessment Report of the Intergovernmental Panel on Climate Change, edited by: Solomon S., Qin, D., Manning, M., Chen, Z., Marquis, M., Averyt, K. B., Tignor, M., and Miller, H. L., Cambridge University Press, Cambridge, UK and New York, NY, USA, 129-234, 2007.

Fougnie, B., Bracco, G., Lafrance, B., Ruffel, C., Hagolle, O., and Tinel, C.: PARASOL in-flight calibration and performance, Appl. Optics, 46, 5435-5451, 2007.

Goloub, P., Deuzé, J.-L., Herman, M., and Fouquart, Y.: Analysis of the POLDER polarization measurements performed over cloud covers, IEEE T. Geosci. Remote, 32, 78-88, 1994.

Hale, G. M. and Querry, M. R.: Optical constants of water in the 200-nm to 200- $\mu \mathrm{m}$ wavelength region, Appl. Optics, 12, 555$563,1973$.

Hansen, J. E. and Travis, L. D.: Light scattering in planetary atmospheres, Space Sci. Rev., 16, 527-610, doi:10.1007/BF00168069, 1974.

Hasekamp, O. P.: Capability of multi-viewing-angle photopolarimetric measurements for the simultaneous retrieval of aerosol and cloud properties, Atmos. Meas. Tech., 3, 839-851, doi:10.5194/amt-3-839-2010, 2010.

Haywood, J. M. and Boucher, O.: Estimates of the direct and indirect radiative forcing due to tropospheric aerosols: A review, Revs. Geophys., 38, 513-543, 2000.

Haywood, J. M., Osborne, S. R., Francis, P., Glew, M., Highwood, E., Formenti, P., and Andreae, M.: Radiative properties and direct radiative effect of Saharan dust measured by the C-130 aircraft during SHADE: 1. Solar spectrum, J. Geophys. Res., 108, 85778592, doi:10.1029/2002JD002687, 2003.

Haywood, J. M., Osborne, S. R., and Abel, S. J.: The effect of overlying absorbing aerosol layers on remote sensing retrievals of cloud effective radius and cloud optical depth, Q. J. Roy. Meteorol. Soc., 130, 779-800, 2004.

Herman M., Deuzé, J.-L., Marchand, A., Roger, B., and Lallart, P.: Aerosol remote sensing from POLDER/ADEOS over the ocean: Improved retrieval using a nonspherical particle model, J. Geophys. Res., 110, D10S02, doi:10.1029/2004JD004798, 2005.
Hsu, N. C., Herman, J. R., and Chen, S.-C.: Radiative impacts from biomass burning in the presence of clouds during boreal spring in southeast Asia, Geophys. Res. Lett., 30, 1224-1227, doi:10.1029/2002GL016485, 2003.

Hu, Y., Vaughan, M., Liu, Z., Powell, K., and Rodier, S.: Retrieving optical depths and lidar ratios for transparent layers above opaque water clouds from calipso lidar measurements, IEEE Geosci. Remote Sens. Lett., 4, 523-526, 2007.

Johnson, B. T., Shine, K. P., and Forster, P. M.: The semidirect aerosol effect: Impact of absorbing aerosols on marine stratocumulus, Q. J. Roy. Meteorol. Soc., 130, 1407-1422, doi:10.1256/qj.03.61, 2004.

Kaufman, Y., Tanré, D., and Boucher, O.: A satellite view of aerosols in the climate system, Nature, 419, 215-223, 2002.

Keil, A. and Haywood, J. M.: Solar radiative forcing by biomass burning aerosol particles during SAFARI 2000: A case study based on measured aerosol and cloud properties, J. Geophys. Res., 108, 8467-8476, 2003.

Knobelspiesse, K., Cairns, B., Redemann, J., Bergstrom, R. W., and Stohl, A.: Simultaneous retrieval of aerosol and cloud properties during the MILAGRO field campaign, Atmos. Chem. Phys., 11, 6245-6263, doi:10.5194/acp-11-6245-2011, 2011.

Leahy, L. V., Anderson, T. L., Eck, T. F., and Bergstrom, R. W.: A synthesis of single scattering albedo of biomass burning aerosol over southern Africa during SAFARI 2000, Geophys. Res. Lett., 34, L12814, doi:10.1029/2007GL029697, 2007.

Lenoble, J., Herman, M., Deuzé, J. L., Lafrance, B., Santer, R., and Tanré, D.: A successive order of scattering code for solving the vector equation of transfer in the earths atmosphere with aerosols, J. Quant. Spectrosc. Ra., 107, 479-507 doi:10.1016/j.jqsrt.2007.03.010, 2007.

Marshak, A. and Davis, A. B.: 3D radiative transfer in cloudy atmospheres, Springer, New York, p. 686, 2005.

Martin, G. M., Johnson, D. W., and Spice, A.: The measurement and parameterization of effective radius of droplets in warm stratocumulus clouds, J. Atmos. Sci., 51, 1823-1842, 1994.

Menzel, W. P., Frey, R. A., and Baum, B. A.: Cloudtop properties and cloud phase algorithm theoretical basis document, version 8 , available online at http://modis-atmos.gsfc.nasa.gov/_docs/CTP_ ATBD_oct10.pdf (last access: April 2013), 63 pp., 2010.

Mishchenko, M. I. and Travis, L. D.: T-matrix computations of light scattering by large spheroidal particles, Opt. Commun., 109, 1621, 1994.

Mishchenko, M. I. and Travis, L. D.: Satellite retrieval of aerosol properties over the ocean using polarization as well as intensity of reflected sunlight, J. Geophys. Res., 102, 16989-17013, 1997.

Nakajima, T. and Tanaka, M.: Algorithms for radiative intensity calculations in moderately thick atmospheres using a truncation approximation, J. Quant. Spectrosc. Ra., 40, 51-69, 1988.

Parol, F., Buriez, J. C., Vanbauce, C., Riedi, J., Labonnote, L. C., Doutriaux-Boucher, M., Vesperini, M., Sèze, G., Couvert, P., Viollier, M., and Bréon, F. M.: Capabilities of Multi-Angle Polarization Cloud measurements from satellite: POLDER results, Adv. Space Res., 33, 1080-1088, 2004.

Peters, K., Quaas, J., and Bellouin, N.: Effects of absorbing aerosols in cloudy skies: a satellite study over the Atlantic Ocean, Atmos. Chem. Phys., 11, 1393-1404, doi:10.5194/acp-11-13932011, 2011. 
Platnick, S., King, M. D., Ackerman, S. A., Menzel, W. P., Baum, B. A., Riédi, J. C., and Frey, R. A.: The MODIS Cloud Products: Algorithms and Examples From Terra, IEEE T. Geosci. Remote, 41, 459-473, 2003.

Politovich, M. K.: A study of the broadening of droplet size distributions in cumuli, J. Atmos. Sci., 50, 2230-2244, 1993.

Potter, J.: The delta function approximation in radiative transfer theory, J. Atmos. Sci., 27, 943-949, 1970.

Ramanathan, V., Crutzen, P. J., Lelieveld, J., Mitra, A. P., Althausen, D., Anderson, J., Andreae, M. O., Cantrell, W., Cass, G. R., Chung, C. E., Clarke, A. D., Coakley, J. A., Collins, W. D., Conant, W. C., Dulac, F., Heintzenberg, J., Heymsfield, A. J., Holben, B., Howell, S., Hudson, J., Jayaraman, A., Kiehl, J. T., Krishnamurti, T. N., Lubin, D., McFarquhar, G., Novakov, T., Ogren, J. A., Podgorny, I. A., Prather, K., Priestley, K., Prospero, J. M., Quinn, P. K., Rajeev, K., Rasch, P., Rupert, S., Sadourny, R., Satheesh, S. K., Shaw, G. E., Sheridan, P., and Valero, F. P. J.: The Indian Ocean Experiment: An Integrated Assessment of the Climate Forcing and Effects of the Great Indo-Asian haze, J. Geophys. Res., 106, 28371-28393, 2001.

Riedi, J., Marchant, B., Platnick, S., Baum, B. A., Thieuleux, F., Oudard, C., Parol, F., Nicolas, J.-M., and Dubuisson, P.: Cloud thermodynamic phase inferred from merged POLDER and MODIS data, Atmos. Chem. Phys., 10, 11851-11865, doi:10.5194/acp-10-11851-2010, 2010.

Rodgers, C. D.: Inverse methods for atmospheric sounding: theory and practice, World Scientific Publishing Co. Ltd, London, UK, p. 238, 2000 .

Rosenfeld, D.: Suppression of rain and snow by urban and industrial air pollution, Science, 287, 1793-1796, 2000.

Salomonson, V. V., Barnes, W. L., Maymon, P. W., Montgomery, H. E., and Ostrow, H.: MODIS: Advanced facility instrument for studies of the Earth as a system, IEEE T. Geosci. Remote, 27, 145-153, 1989.

Tanré D., Bréon, F.-M., Deuzé, J.-L., Herman, M., Goloub, P., Nadal, F., and Marchand, A.: Global observation of anthropogenic aerosols from satellite, Geophys. Res. Lett., 28, 45554558, 2001.

Torres, O., Jethva, H., and Bhartia, P. K.: Retrieval of Aerosol Optical Depth above Clouds from OMI Observations: Sensitivity Analysis and Case Studies, J. Atmos. Sci., 69, 1037-1053, doi:10.1175/JAS-D-11-0130.1, 2012.
Twomey, S.: The influence of pollution on the shortwave albedo of clouds, J. Atmos. Sci., 34, 1149-1152, 1977.

Vanbauce, C., Cadet, B., and Marchand, R. T.: Comparison of POLDER apparent and corrected oxygen pressure to ARM/MMCR cloud boundary pressures, Geophys. Res. Lett., 30, 1212-1215, doi:10.1029/2002GL016449, 2003.

Vaughan, M., Young, S., Winker, D., Powell, K., Omar, A., Liu, Z., Hu, Y., and Hostetler, C.: Fully automated analysis of spacebased lidar data: an overview of the CALIPSO retrieval algorithms and data products, in: Laser Radar Techniques for Atmospheric Sensing, edited by: Singh, U. N., International Society for Optical Engineering, Proc. SPIE, 5575, 16-30, doi:10.1117/12.572024, 2004.

Volten, H., Munõz, O., Rol, E., de Haan, J. F., Vassen, W., Hovenier, J. W., Muinonen, K., and Nousiainen, T.: Scattering matrices of mineral aerosol particles at $441.6 \mathrm{~nm}$ and $632.8 \mathrm{~nm}$, J. Geophys. Res., 106, 17375-17401, 2001.

Wang, P., Tuinder, O. N. E., Tilstra, L. G., de Graaf, M., and Stammes, P.: Interpretation of FRESCO cloud retrievals in case of absorbing aerosol events, Atmos. Chem. Phys., 12, 90579077, doi:10.5194/acp-12-9057-2012, 2012.

Waquet, F., Goloub, P., Deuzé, J.-L., Léon, J.-F., Auriol, F., Verwaerde, C., Balois, J.-Y., and François, P.: Aerosol retrieval over land using a multiband polarimeter and comparison with path radiance method, J. Geophys. Res., 112, D11214, doi:10.1029/2006JD008029, 2007.

Waquet, F., Riedi, J., Labonnote, L. C., Goloub, P., Cairns, B., Deuzé, J.-L., and Tanré, D.: Aerosol remote sensing over clouds using the A-Train observations, J. Atmos. Sci., 66, 2468-2480, doi:10.1175/2009JAS3026.1, 2009a.

Waquet, F., Cairns, B., Knobelspiesse, K., Chowdhary, J., Travis, L. D., Schmid, B., and Mishchenko, M. I.: Polarimetric remote sensing of aerosols over land, J. Geophys. Res., 114, D01206D01228, doi:10.1029/2008JD010619, 2009b.

Wilcox, E. M.: Direct and semi-direct radiative forcing of smoke aerosols over clouds, Atmos. Chem. Phys., 12, 139-149, doi:10.5194/acp-12-139-2012, 2012.

Winker, D. M., Hunt, W. H. and Hostetler, C. A.: Status and performance of the CALIOP lidar, in: Laser Radar Techniques for Atmospheric Sensing, edited by: Singh, U. N., International Society for Optical Engineering, Proc SPIE, 5575, 8-15, doi:10.1117/12.571955, 2004. 